\section{O consumo de álcool segundo as gravuras Beer Street e Gin Lane de William Hogarth e as obras de John Wesley: convergências e diferenças}

\author{
Alcohol consumption as \\ portrayed in William \\ Hogarth's prints Beer Street \\ and Gin Lane and in the \\ works of John Wesley: \\ similarities and differences
}

\section{Helmut Renders}

Professor da Faculdade de Teologia e do Programa de Pós-graduação em Ciências de Religião/ Universidade Metodista de São Paulo.

Rua do Sacramento, 230

09640-000 - São Bernardo do Campo - SP - Brasil

helmut.renders@metodista.br

Recebido para publicação em dezembro de 2010. Aprovado para publicação em maio de 2011.
RENDERS, Helmut. O consumo de álcool segundo as gravuras Beer Street e Gin Lane de William Hogarth e as obras de John Wesley: convergências e diferenças. História, Ciências, Saúde Manguinhos, Rio de Janeiro, v.19, n.4, out.-dez. 2012, p.1191-1218.

\section{Resumo}

Compara as gravuras Gin Lane e Beer Street, de William Hogarth, com textos do seu contemporâneo John Wesley, spiritus rector do movimento religioso metodista. Embora em algumas gravuras Hogarth tenha retratado o movimento metodista como perigosamente entusiasta, os dois defenderam uma agenda próxima quanto ao consumo de álcool. A semelhança entre as duas formas de compreender a questão é explicada por costumes culturalmente estabelecidos, e a diferença por uma perspectiva social distinta.

Palavras-chave: William Hogarth (1697-1764); John Wesley (17031791); consumo de álcool; religião; Inglaterra.

\section{Abstract}

The article compares William Hogarth's Gin Lane and Beer Street with texts by his contemporary John Wesley, spiritus rector of the Methodist movement. Although Hogarth had portrayed the Methodist religious movement in some of his prints as dangerously enthusiastic, both men defended a similar agenda concerning alcohol consumption. The similarities in their two ways of understanding the issue can be explained by culturally established customs, while distinct social outlooks can account for their differences.

Keywords: William Hogarth (1697-1764); John Wesley (1703-1791); alcohol consumption; religion; England. 
$\mathrm{O}$ consumo de álcool é um tema cultural e socialmente relevante pela ampla difusão da questão, e consequentemente por seus efeitos tanto na saúde como na segurança pública, bem como pela discussão dos prós e dos contras levantada por médicos e religiosos.

Neste artigo, propomos comparar duas manifestações: as gravuras Gin Lane e Beer Street, de 1751, de William Hogarth (1697-1764), e as passagens referentes ao consumo individual de álcool contidas nas obras de John Wesley (1703-1791). Wesley, sacerdote anglicano, liderou um movimento religioso chamado metodismo, cujo objetivo, segundo ele, era reformar a nação e a Igreja. Hogarth, também anglicano, produziu "ilustrações satíricas e sermões leigos"1 $^{1}$ (Sala, 1866, p.302). Ambos se preocupavam com a saúde pública e alertaram para o efeito devastador do consumo exagerado de álcool. Hogarth, entretanto, representava o anglicanismo oficial e desconfiava do movimento metodista.

$\mathrm{Na}$ gravura The idle prentice executed at Tyburn (O aprendiz preguiçoso executado em Tyburn), de $1747^{2}$, Hogarth retratou Silas Todd, leigo metodista que atuava nas prisões entre os detentos. Apesar de a historiografia metodista destacar o fato de o grande moralista inglês Hogarth ter abordado esse engajamento social ${ }^{3}$, Hogarth considerava Todd alguém que investia em pessoas erradas no momento errado: no ciclo das gravuras de Hogarth, a gravura o Executado em Tyburn era a última da série chamada Aprendiz preguiçoso, que retratava pessoas que, segundo o gravurista, mereciam a morte. A gravura Credulity, superstition, and fanaticism (Credulidade, superstição, e fanatismo), criada 15 anos depois, em 1762, mostra a impressão basicamente negativa de Hogarth sobre os metodistas, retratados como entusiastas e politicamente perigosos. ${ }^{4}$

Parece-nos, então, correto concluir que os dois, apesar de pertencerem à mesma Igreja, representavam grupos distintos, com perspectivas diferentes. Pretendemos explorar essas diferenças, para verificar se e como aparecem em suas afirmações em relação ao consumo de álcool.

\section{O contexto}

No início do século XVIII, com a entrada em cena do gim, a discussão sobre o consumo de bebidas alcoólicas assumiu uma nova fase na Inglaterra. Até o fim do século XVII, tinha-se mantido "uma estratificação social do [uso do] álcool", cuja divisão era relacionada, em geral, ao consumo de "vinho cortês, cerveja urbana e ale bucólico"s (Nicholls, 2010, p.12). O gim, bebida holandesa que se tornou conhecida entre os ingleses durante a chamada Guerra dos Oito Anos (1568-1609), tornou-se popular na Inglaterra cem anos depois, durante o reinado do holandês Guilherme III (1650-1702). Contribuíram para sua aceitação por parte do Estado interesses do mercado interno, pois depois de 1689, na fase da Restauração inglesa, procurava-se estabilizar o preço dos grãos por meio do aumento de produção de aguardentes (Gately, 2008, p.162-163).

O gim era uma bebida barata, com um teor alcoólico de $47 \%$, ou seja, maior do que o do uísque escocês (35\%), cujo uso era pouco difundido. Uma primeira tentativa, em 1729, de restringir a produção de gim e permitir sua venda somente em estabelecimentos licenciados (Gately, 2008, p.163) causou revoltas sociais. Em consequência, bairros pobres 
de Londres, como Saint Giles - que foi retratado na gravura Gin Lane de Hogarth -, foram tomados por pontos de venda.

A liberação fática do consumo excessivo de álcool de alta graduação funcionava como válvula de escape para as camadas mais humildes da sociedade inglesa e, ao mesmo tempo em que impedia, criava tensões sociais. Somente em 1751, na quarta tentativa, foi criada uma legislação capaz de sanar os problemas mais graves.

\section{As fontes}

Apresentamos aqui as fontes em ordem cronológica. Os textos são referenciados sempre de acordo com sua primeira edição, as edições posteriores são mencionadas somente quando apresentam mudanças.

O primeiro grupo de textos é de John Wesley, de 1743, The nature, design, and general rules of the United Societies (A natureza, estrutura e as regras gerais das Sociedades Unidas) e "On the use of money" (Sobre o uso do dinheiro); 1745, A word in season, or, advice to a soldier (Uma palavra oportuna ou um conselho para um soldado); 1746, A collection of receits for the use of the poor (Coletânea de receitas para uso dos pobres); 1747, Primitive physick (Medicina popular) e 1748, A word to a drunkard (Uma palavra para um bêbado). Depois da análise das gravuras de Hogarth, de 1751, seguem novamente textos de Wesley, de 1755, Explanatory notes upon the New Testament (Notas explicativas sobre o Novo Testamento); 1771, Journal (Diário); 1773, Thoughts on the present scarcity of provisions (Pensamentos sobre a atual escassez de provisões); 1783, "On the education of children" (Sobre a educação de crianças) e 1790 "A moral and physickal thermometer..." (Um termômetro moral e físico...).

\section{3 - O tema da temperança segundo as "Regras gerais": “Não embriagar-se; ... não comprar ou vender bebidas fortes..."}

O primeiro texto de John Wesley, as chamadas "Regras gerais", era um documento fundamental nas sociedades metodistas, e sua observação regulava a permanência nessas associações religiosas livres. As regras foram formuladas em 1743 e publicadas pela primeira vez em 1745 (1745b), ou seja, no início da fase da organização do movimento metodista. Citamos uma parte das "Regras gerais" (Campbell, 2012, p.144-146):

Em primeiro lugar: Não causar dano, evitando todos os tipos de mal, especialmente aqueles que são mais comumente praticados, tais como: Tomar o nome de Deus em vão. Profanar o Dia do Senhor .... Embriaguez: comprar e vender bebidas fortes, a menos em casos de necessidade. Posse de escravos; compra e venda de escravos. ...

Segundo: Fazendo o bem; sendo misericordiosos de todas as formas conforme sua capacidade; quando houver oportunidade, fazendo o bem de todas as formas possíveis, e, na medida do possível, a todos os homens: ...

Terceiro: Obedecendo a todos os mandamentos de Deus; tais como:

O culto público a Deus, o ministério da Palavra, seja lida ou exposta. A Ceia do Senhor. A oração particular e em família. Estudar as Escrituras. Jejum ou abstinência. ${ }^{6}$ 
Quanto ao tema deste artigo, o texto original dá quatro orientações-chave. Primeiro, a embriaguez é considerada um mal "comumente praticado" que deve ser, sem exceção, enfrentado. Não se ignora essa realidade, entendida como fenômeno cultural, nem se minimiza seu efeito. Como a embriaguez representa um mal que, a longo ou curto prazo, coloca a vida da própria pessoa e de outras pessoas em risco, ela não pode ser reduzida a um pecadilho. Ela representa ou uma ilusão - que a embriaguez traria felicidade -, ou falta de autoconhecimento ou de conhecimento do produto ingerido. Enfim, ela é, no mínimo, indicativa de falta de maturidade e, com certeza, insalubre. Em segundo lugar, o texto tematiza certa classe de bebidas, as bebidas fortes (strong liquors). Aqui devemos pensar em gim e equivalentes. Não se vê utilidade em seu consumo ou em sua liberação. Em terceiro lugar, as regras falam de "comprar e vender", ou seja, de uma atividade econômica. Lucrar acima do razoável, ademais, com provável prejuízo de terceiros, é considerado inadmissível para membros das sociedades metodistas. Em quarto lugar o texto refere-se também à abstinência. Entretanto, essa é vinculada a uma prática com prazo definido, mesmo sendo ela exercitada com regularidade - no caso, cada quarta-feira e sexta-feira da semana. Devemos imaginar que se trata de um jejum ou de uma abstinência que envolve tanto comida quanto bebida, porém, por um período determinado, não por toda a vida.

Os acréscimos posteriores, de igrejas metodistas nos EUA, documentados ao final da nota 6, datam da segunda metade do século XVIII. Eles não dão continuidade à proposta original da temperança, favorecendo o modelo da abstinência completa e contínua de todos os tipos de álcool.

Independentemente do tipo de bebida consumido, o texto critica a embriaguez, considerada falta de temperança, a venda de bebidas fortes, considerada uma prática econômica ilícita e a sua compra, considerada imprudente.

1743 - O tema de lucro com a venda de gim no sermão "Sobre o uso do dinheiro": "Todos os que vendem bebidas a quem queira comprar são envenenadores do público"

Em 1743, Wesley pregou o sermão "Sobre o uso do dinheiro". Na sua primeira coletânea de sermões, publicada entre 1746 e 1787, esse está identificado como sermão 44 (Wesley, 1787). Nele o autor desenvolve as três premissas de uma economia justa: "Ganhai o mais que puderdes"; "Economizai o mais que puderdes" e "Dai o mais que puderdes". Como exemplo inaceitável de lucro, Wesley (1787, p.602 e ss.) cita a produção e a venda de licores ou bebidas alcoólicas:

I.4 [Não] podemos ganhar, prejudicando nosso próximo em seu corpo. Portanto, não podemos vender coisa alguma que tenda a arruinar-lhe a saúde. Tal acontece eminentemente com aquele fogo líquido, comumente chamado licor ou bebida alcoólica. É verdade que tais bebidas podem ter aplicação na medicina; ... Prepará-las, portanto, e vendê-las somente para esse uso [uso médico] pode ser ato que se pratique com a consciência limpa. Mas quem assim procede? Quem prepara bebidas somente para fins terapêuticos? Conheceis dez desses destiladores na Inglaterra? Então os desculpai. Mas todos os que vendem bebidas ... a quem queira comprar, são envenenadores do público. Assassinam por atacado os súditos de Sua Majestade, sem dó nem piedade. Conduzem-nos ao inferno como um rebanho. E qual é seu lucro? Não é o sangue desses homens?7 
O alvo da crítica agora são, ao lado dos vendedores, também os produtores. O resultado dos seus empreendimentos é visto como exclusivamente negativo. Eles são categorizados como "envenenadores do público". Talvez haja aqui também uma referência à relação entre o consumo deliberado do gim e o aumento da criminalidade (Gately, 2008, p.163). O vendedor não deve somente olhar para o seu palácio luxuoso financiado legalmente pelo negócio da bebida. Ele precisa ser denunciado pelo efeito social do seu ato. Como argumento ex silentio notamos, tanto neste caso como nas "Regras gerais", que não se fala de cerveja, nem da venda de outras bebidas com teor alcoólico mais baixo.

\section{5 - O serviço militar tolera a embriaguez e facilita crimes}

Num dos seus pequenos tratados dirigidos aos soldados, Wesley (1745a, p.5-6) explicita que "embriaguez, vingança, fornicação, adultério" acompanham a profissão. Nesse caso, a embriaguez é vista como facilitadora das três práticas mencionadas em seguida. Fornicação e adultério referem-se provavelmente à procura de prostitutas por soldados; vingança, talvez, às crueldades cometidas que iam além dos deveres do soldado de desmobilizar ou desarmar seu inimigo. Novamente, o descontrole é o alvo do julgamento, da censura, apesar de Wesley ter mantido durante toda a sua vida uma posição muito crítica em relação a qualquer tipo de guerra.

\section{6 - O tema da temperança segundo o guia medicinal “Coletânea de receitas para uso dos pobres"}

Em 1746, Wesley publicou seu primeiro guia medicinal, "Coletânea de receitas para uso dos pobres". Em termos do uso medicinal de álcool, o texto refere-se seis vezes ao uso de vinho (Wesley, 1746, p.5, 7, 9, 13, 14, 15). Na página 5 (receita 35), aconselha-se tomar um remédio ou com água ou com vinho; na p.7 (receita 60), p.9 (receita 144) e p.14 (receita 168), recomenda-se tomar um remédio com uma taça de vinho branco. Tais propostas de uso correspondem à permissão do uso medicinal "em casos de necessidade", encontrada tanto nas "Regras gerais" como no sermão 50.

\section{7 - 0 tema da temperança segundo o guia medicinal Primitive physick: "exceto uma cerveja clara ou leve"}

O guia medicinal popular Primitive physick circulou entre 1747 e 1791, ano da morte de John Wesley. Trata-se do seu texto mais reeditado, com 23 edições, e que foi publicado até 1760 de forma anônima. Ao já comentado "Coletânea de receitas..." (Wesley, 1746) o texto acrescenta uma introdução que contém conselhos do doutor George Chyene (Wesley, 1747, p.XIII), originalmente endereçada às elites dos urban idle rich (citadinos ricos e preguiçosos) (Turner, 1996, p.168, 169). Wesley popularizou essas recomendações entre as populações urbanas e rurais pobres e manteve essa introdução em todas as reedições. Nessa parte, o guia Primitive physick (Wesley, 1747, p.XX) distingue duas classes e diversos tipos de bebidas alcoólicas: ${ }^{8}$

[8.] Licores fortes não conseguem prevenir os males de um excesso, nem ajudam a superar seus efeitos de forma tão segura quanto a água. 
[9.] Licores de malte (exceto uma cerveja clara ou leve [ou um pequeno ale], em seu período de validade) são bastante prejudiciais para pessoas frágeis [ou sensíveis]. ${ }^{9}$

'Licores de malte' são cervejas. A mais conhecida, a porter, tinha de $6 \%$ a 9,5\% de álcool e era uma cerveja tipo ale. Uma pale ale, por sua vez, tinha cerca de 4,6\% de álcool, e uma 'cerveja clara ou leve', small beer, aproximadamente 2,6\%. A partir da edição de 1781, Wesley refere-se também a uma 'pequena ale' (small ale). Isso parece ter sido uma adaptação linguística, porque nessa época acabou-se usando small ale como sinônimo de small beer.

Todos esses tipos de cervejas fizeram parte da "dieta das classes dos trabalhadores do século XVIII"10 (Olsen, 1999, p.86, 234). A porter foi normalmente produzida e vendida em tavernas, já a cerveja leve era produzida em casa. Isso explica a orientação "em seu período de validade". Uma cerveja leve era bebida durante todo o dia (Royal College, 2000, p.189). ${ }^{11}$ A água não era uma bebida comum no século XVIII, como lembra Macfarlane (2003, p.128): "Parece ter havido diversas razões para beber cerveja em lugar de água. Uma, sem dúvida alguma, era prevenir doenças". ${ }^{12}$ Por trás desses conselhos transparecem técnicas culturais (hábitos) orientadas por questões higiênicas, como a péssima qualidade da água, já mencionada (Sinclair, Sinclair, 2010, p.151). Mas havia também um aspecto socioeconômico. Conforme Thompson (1987, p.183):

\begin{abstract}
A preparação caseira de cerveja suave era tão essencial para a economia doméstica que 'se uma moça soubesse preparar um bolo de aveia e uma boa cerveja, seguramente daria uma boa esposa'; por outro lado 'alguns líderes de grupos metodistas afirmavam que não podiam conduzir suas turmas sem tomar antes uma 'caneca' de bebida'. O declínio do consumo foi atribuído diretamente ao imposto sobre o malte - um imposto tão impopular que alguns contemporâneos consideravam-no uma incitação à revolução. ... O efeito dos impostos foi, indubitavelmente, a grande redução da produção e do consumo doméstico de cerveja (grifo do original).
\end{abstract}

Segundo Thompson (1987), a troca da cerveja simples ou suave pelo chá foi resultado de políticas públicas ${ }^{13}$, e não de dúvidas em relação ao consumo de álcool ou de convicções religiosas. Ao contrário, Wesley ainda considerava que o chá, assim como o café, não eram bebidas saudáveis. O fato de as obras de Wesley serem citadas até 1816 por outros líderes metodistas - o núcleo da estrutura eclesiástica metodista na época - corrobora a permanência ou prevalência de sua posição.

Já em relação à porter, Wesley (1747) aconselhava observar a constituição física da pessoa que iria ingeri-la e sua capacidade de consumir álcool. Provavelmente, se referia aqui a pessoas com estômago sensível, fenômeno que distingue claramente dos 'nervos fracos' (weak nerves) do quais fala em outra passagem do texto.

Além da cerveja, em Primitive physick há referências também ao vinho, ao rum e ao licor. O uso do vinho segue o modelo do primeiro guia medicinal de 1746. Entretanto, no decorrer dos anos, o número de usos aumentou de 14, em 1747 (Wesley, 1747, p.29, 47, 48, $51,59,61,66,68,79,82,95,99,112,113$ ), para 22, em 1791 (Wesley, 1791, p.25, 28, 29, $48,51,58,59,69,71,72,74,78,80,82,84,86,90,91,97,99,101,112)$. Em relação ao rum é mencionado apenas seu uso em aplicações externas (Wesley, 1747, p.35; 1791, p.36, 71). Também são encontradas referências ao uso medicinal de licores: pessoas expostas aos 
ventos do leste ou do norte poderiam "beber licor diluído e quente antes de ir para a cama" (Wesley, 1747, p.XIX).

\section{8 - “Uma palavra para um bêbado": “Deus te fez homem. Por que você se transforma em um animal?"}

O discurso do panfleto "Uma palavra para um bêbado", de 1748, é apresentado em forma de perguntas e respostas:

1. Vocêe um homem? Deus fez você um 'homem'. Mas você se transforma em um 'animal'. Não um louco, não somente um doido, mas um 'porco', um pobre e imundo porco. ...

3. E assim você agora está pronto para 'todo tipo' de 'obra do diabo'....

4. O que vai agora impedir que você passe pela mesma experiência daquele a quem foi perguntado: Qual é o maior pecado: adultério, embriaguez ou assassinato? ... Respondeu ele que a embriaguez seria o menor. Logo em seguida, embriagou-se, encontrou a mulher de outro homem e a violentou. Quando o marido quis ajudá-la, assassinou-o. Ou seja: embriaguez, adultério e assassinato andam juntos....

8. Não tente se desculpar. Não diga como tantos: 'Não sou o inimigo de ninguém, somente de mim mesmo' .... Mas não é o caso. Você é o inimigo do Rei. ... Um embriagado é um inimigo público....

9. Sobretudo, você é um inimigo de Deus....

10. Você é um inimigo de Cristo....

11. Ó, arrependa-se! Encare e sinta a sua desgraça.... Ore para que você possa se conhecer melhor, por dentro e por fora, e todo seu pecado, toda sua culpa, todo seu desamparo. Então grite: Filho de Davi, tenha misericórdia de mim ... para que eu ame muito, porque fui muito perdoado! (Wesley, 1748, p.1-4). ${ }^{14}$

O panfleto de quatro páginas representa bem o drama da dependência, inclusive a consequente inclinação maior para cometer crimes graves: "embriaguez, adultério e assassinato andam juntos". Também aponta justificativas irresponsáveis, em consequência da dependência. O texto não culmina em uma proibição geral do consumo de álcool, mas apela à responsabilidade humana, recomendando não cair no exagero, em outras palavras, não ficar embriagado.

\section{1 - As gravuras Beer Street e Gin Lane de William Hogarth: a defesa da cerveja inglesa e a rejeição ao gim holandês}

As duas gravuras de William Hogarth que serão analisadas a seguir foram publicadas em 1751, no mesmo ano em que o governo inglês conseguiu implantar uma legislação capaz de restringir e regulamentar a produção e venda de gim. É evidente que Hogarth não expressava somente uma opinião pessoal, mas uma percepção mais ampla de diversos setores da sociedade inglesa.

Para facilitar a interpretação e a comparação entre as gravuras e os textos de John Wesley, propusemos um recorte dessas imagens.

A primeira delas, Beer Street (Hogarth, 1751a), retrata cenas de tavernas e refere-se à cerveja porter, relacionando seu consumo ao progresso da sociedade e ao bem-estar geral (Figura 1). 
Helmut Renders

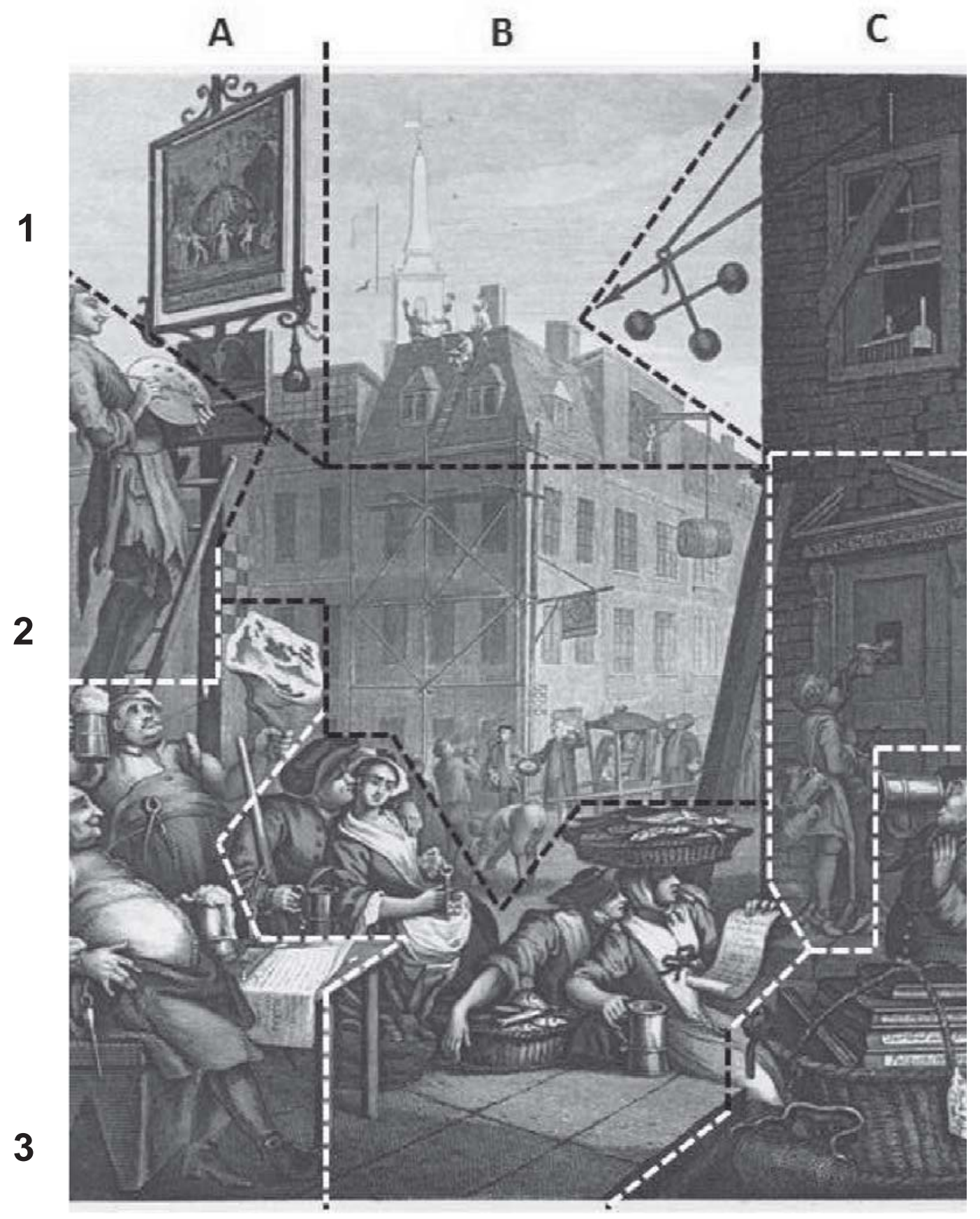

Figura 1: Beer Street, com recortes do autor (Hogarth, 1751a) 
O grupo de sete pessoas no primeiro plano da gravura compõe seu centro. Elas parecem bem de vida e, segundo os critérios da época, bem de saúde. O que chama nossa atenção em primeiro lugar são os dois pares no centro (3B). As cenas retratam relações carinhosas e próximas. Ambas estão localizadas em uma taverna. A primeira envolve um homem e uma moça (Figura 2). ${ }^{15}$

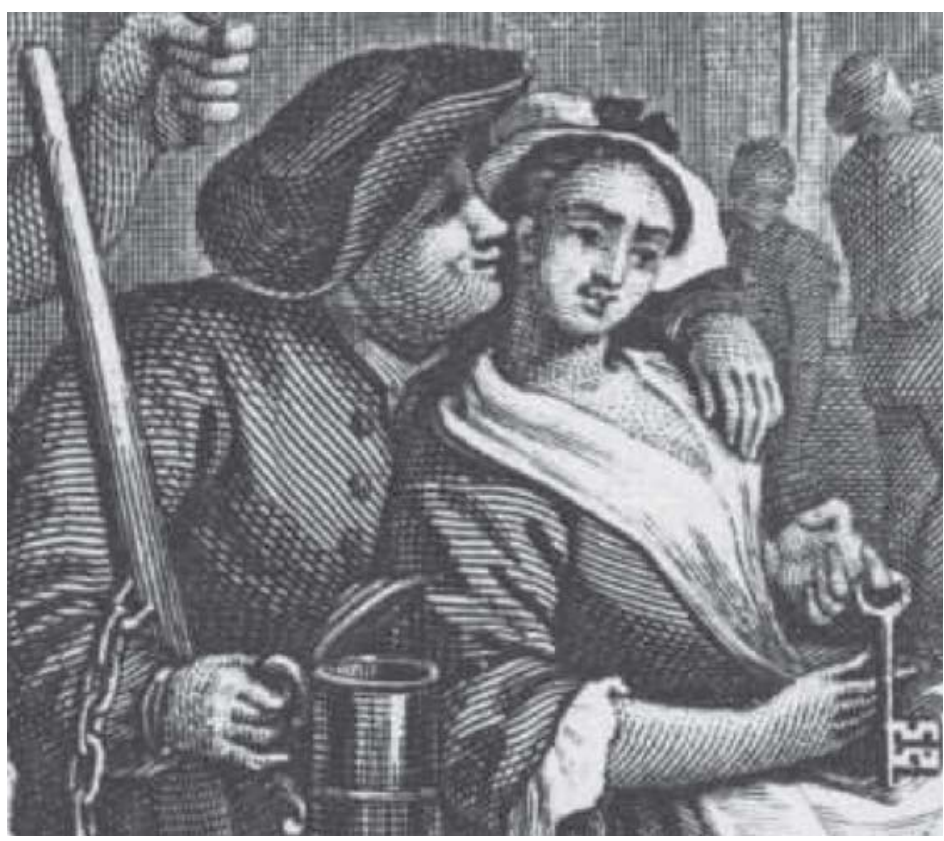

Figura 2: O homem e a moça (ampliação do setor 3B da Figura 1; Hogarth, 1751a)

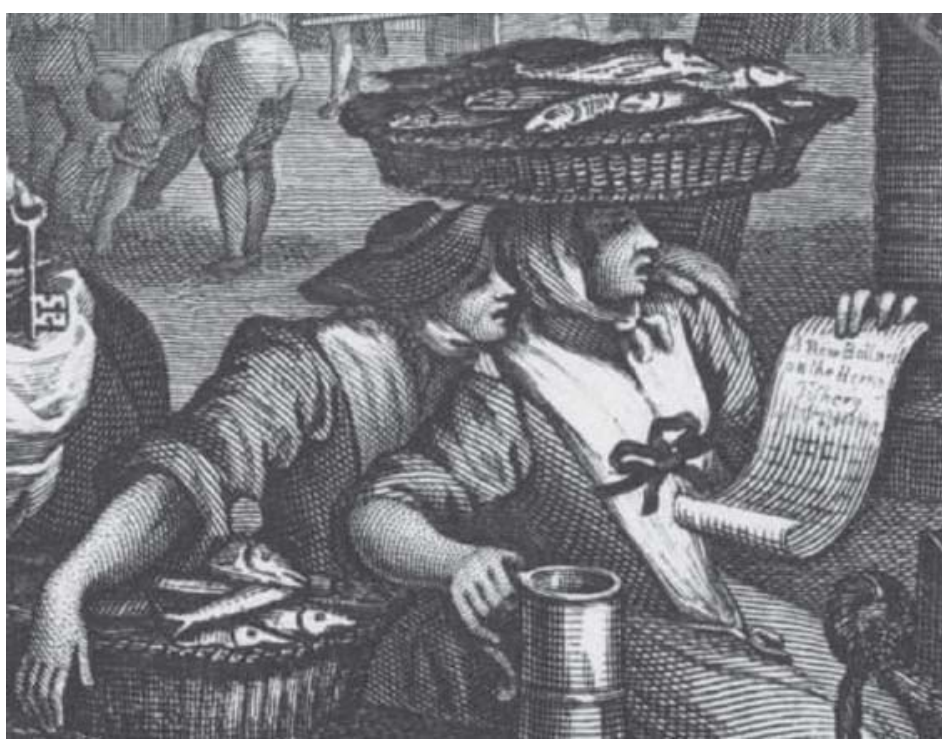

Figura 3: As vendedoras de peixe (ampliação do setor 3B da Figura 1; Hogarth, 1751a)
Um homem, com uma caneca de cerveja na mão, envolve com a outra o colo de uma mulher jovem. Essa segura uma chave, símbolo da sua virtude, talvez, no sentido de preservar-se de uma relação sexual sem compromisso. Nesse caso, poderia representar o oposto da figura feminina central da gravura Gin Lane (ver Figura 7).

O segundo par retrata duas vendedoras de peixe (Figura 3), das quais uma também bebe cerveja. Ambas parecem felizes por interromper por um momento seu trabalho e examinam com interesse o texto de uma canção sobre pesca.

À esquerda desses dois pares (Figura 1, setor 3A) encontram-se dois homens que, a um primeiro olhar, parecem ser vendedores ou produtores de cerveja. Pelos instrumentos pendurados em suas roupas, no entanto, é possível perceber que um deles deve ser dentista, ou talvez ferreiro. Ele segura, além da cerveja, um presunto defumado. O outro, no canto inferior esquerdo, é um açougueiro. Esses dois personagens são gordos, assim como o vendedor de livros (Figura 1, setor 3C) e o cidadão carregado em uma liteira (Figura 1, setor 2B). Para a época, isso significava que eram prósperos.

$\mathrm{Na}$ extrema direita encontramos um trabalhador ambulante e um vendedor de livros, que também estão bebendo uma cerveja (Figura 1, setor 3C). 
O grande número de textos escritos representados na gravura insinua que a maioria das pessoas nela representada sabe ler, ou seja, tem formação escolar. Assim, sinaliza-se que diligência, disposição, educação e o consumo moderado de cerveja não estão em contradição.

No teto de uma das edificações (Figura 4), carpinteiros celebram a finalização do seu trabalho, bebendo cerveja. Obviamente, não estão perdendo o equilíbrio (o que indicaria embriaguez) e contribuem para uma cidade bem construída e em expansão.

Todos os prédios estão em perfeito estado, exceto a loja do penhorista, que parece arruinada. O símbolo que permite reconhecer o penhorista (três esferas suspensas de uma barra) está quebrado (Figura 1, setor 1C; comparar com a Figura 7, setor 1A). As ruas estão livres e a circulação é fácil (Figura 5).

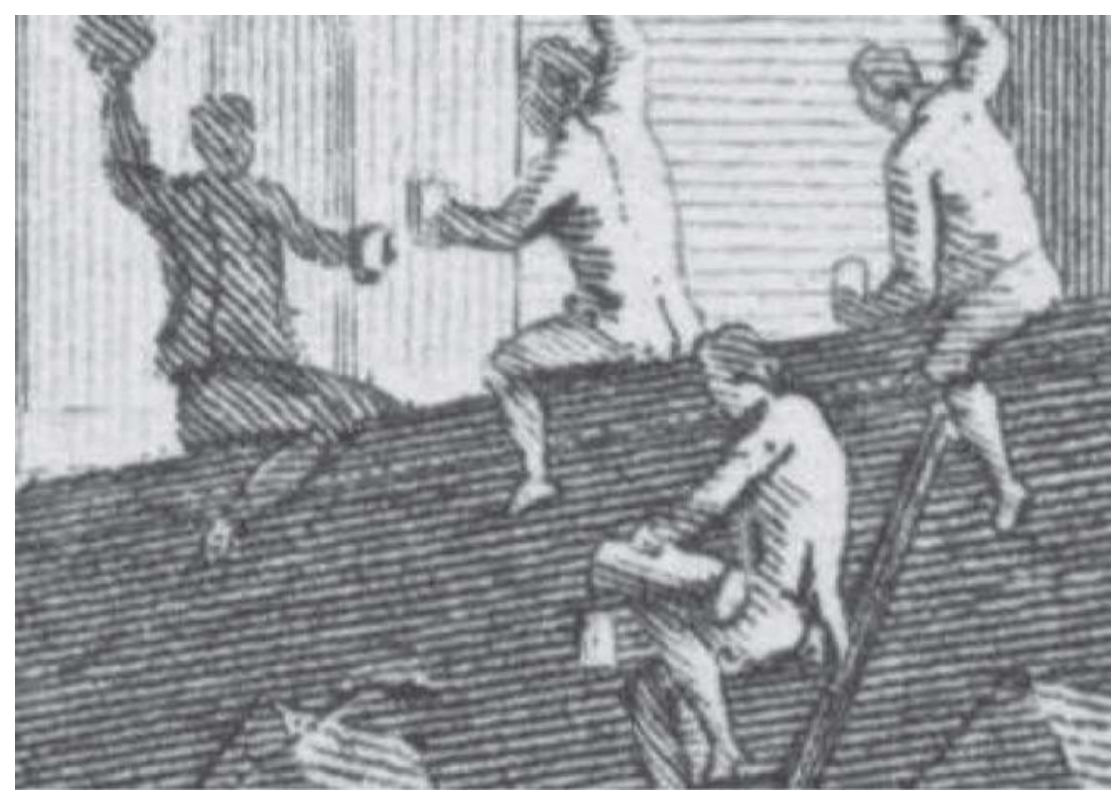

Figura 4:

Carpinteiros celebrando a conclusão de uma obra (ampliação do setor 1B da Figura 1; Hogarth, 1751a)

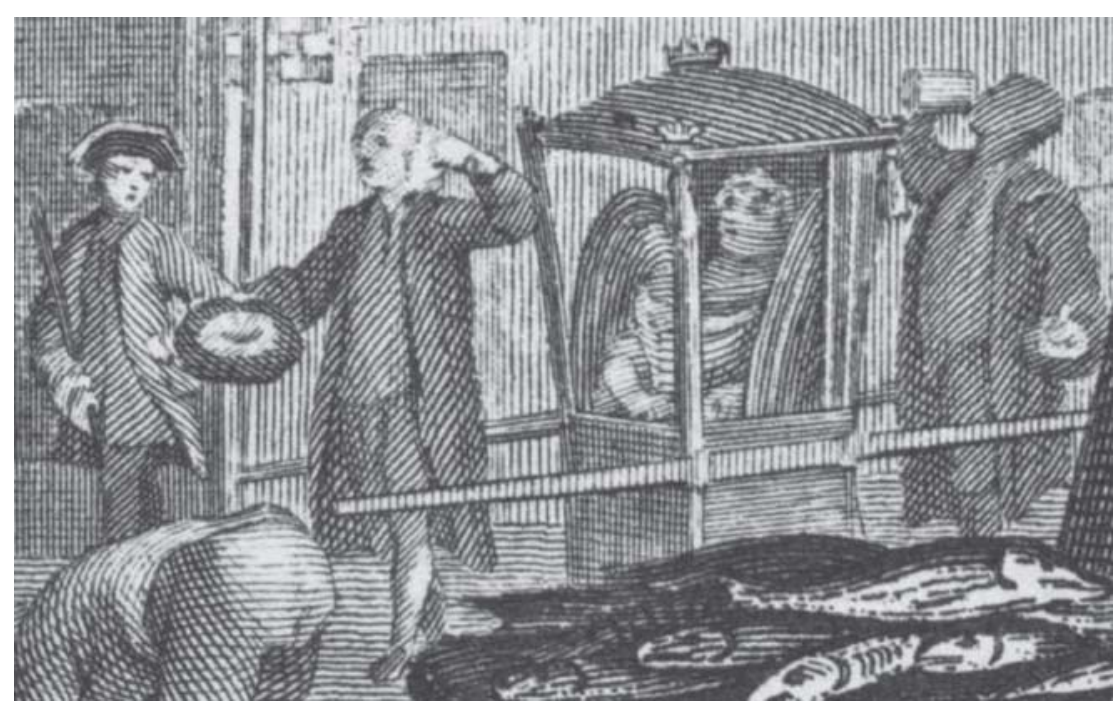

Figura 5: Cidadão carregado em uma liteira (Ampliação do setor $2 \mathrm{~B}$ da Figura 1; Hogarth, 1751a) 
Note-se que uma das pessoas que carrega o cidadão na liteira também está tomando uma cerveja.

Um pintor retrata na placa da taverna (Figura 6) uma cena de dança, ou seja, uma atividade comunitária e festiva. Sendo uma cena rural, remete à idealização do rural na perspectiva urbana típica do século XVIII. A frase "Health to the Barley-Mow" (Um brinde à cevada!), lembra um cereal fundamental para a produção de cerveja e servia para nomear canções de bebedeira (drinking songs).

Na segunda gravura aqui analisada, Gin Lane, Hogarth (1751b) retratou um alerta em relação aos efeitos das bebidas fortes (strong liquors) que se tornou emblemático na sua época.

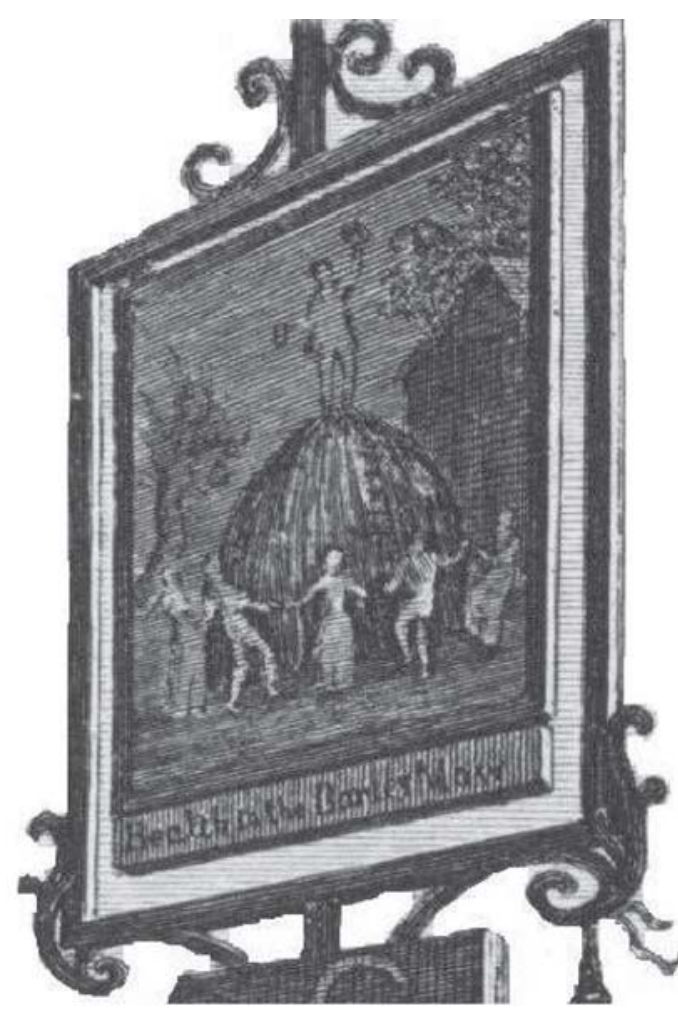

Figura 6: A placa da taverna (ampliação do setor 1A da Figura 1; Hogarth, 1751a)

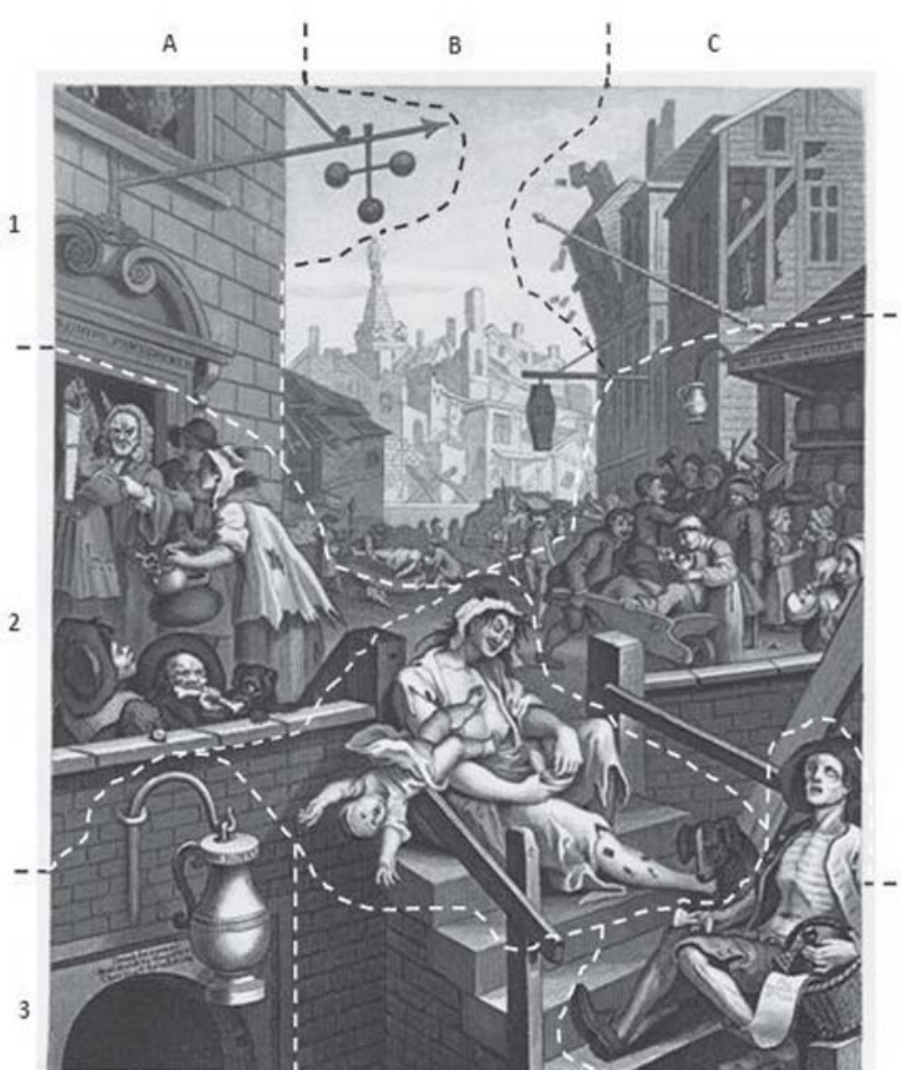

Figura 7: Gin Lane, com recortes do autor (Hogarth, 1751b)

A gravura não deixa dúvida alguma em relação ao estado de calamidade causado pela ampla oferta de gim barato. Segundo essa obra, o mundo inglês estava à beira da desconstrução total da ordem e da segurança social. Não por acaso, Hogarth (1751b) retrata aqui o bairro londrino de Saint Giles (Sala, 1866; Paulson, 1993, p.448).

No centro da gravura (Figura 7) tematiza-se a destruição dos relacionamentos humanos e familiares e o abandono das crianças (Figura 7, setores 2B e 2C). Pelas feridas abertas nas pernas da mulher, é possível supor que ela seja sifilítica, provavelmente em consequência 
da prostituição. O homem, ainda de uniforme (Figura 7, setor 3C), havia sido soldado. Ele tenta vender panfletos, mas obviamente é malsucedido em seu empreendimento. Todas as figuras são magras, e algumas parecem ser de mortos-vivos.

A morte está muito presente nessa gravura. Em 2A/1B (Figura 8), encontra-se uma cena de funeral em que uma mulher morta, sem roupas, é colocada em um caixão, enquanto uma criança pequena, possivelmente um filho, chora ao seu lado.

A terceira cena que envolve a relação entre mãe e criança pequena encontra-se no setor 2C (Figura 9). Nela, observa-se uma mãe dando gim ao seu bebê, provavelmente para mantê-lo quieto, um recurso indevidamente empregado na época.

Os vendedores de bebida precisavam quebrar a possível resistência de novos clientes. Para isso, havia estratégias visando tornar e manter as pessoas dependentes do álcool: oferecer-lhes bebidas constantemente. Na Figura 10, algumas pessoas parecem ser forçadas a consumir bebida. Essa parte da gravura mostra ainda que o consumo de gim leva a brigas.

Para sustentar a dependência, as pessoas vendem suas ferramentas de trabalho para um penhorista (Figura 11), curiosamente, chamado de senhor Pega ${ }^{16}$ na gravura. Elas comprometem a base do seu próprio

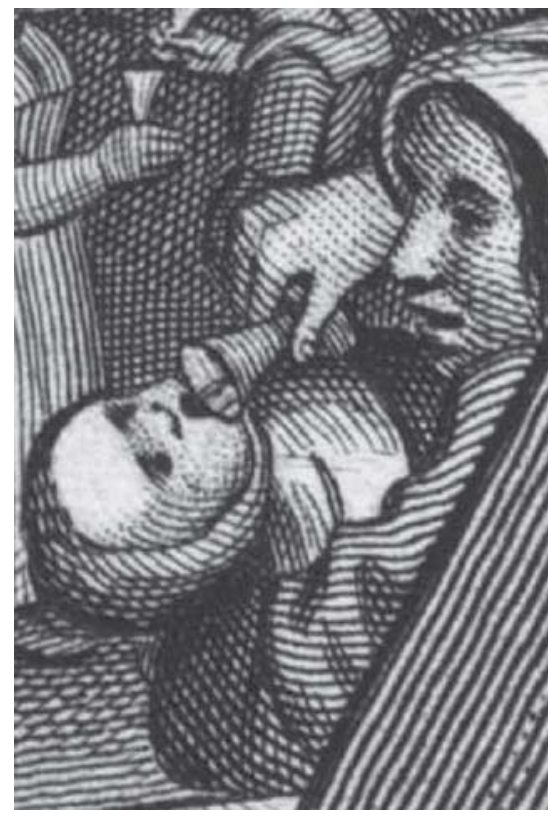

Figura 9: Uma mãe dá gim para o bebê (Ampliação do setor 2C da Figura 7; Hogarth, 1751b)

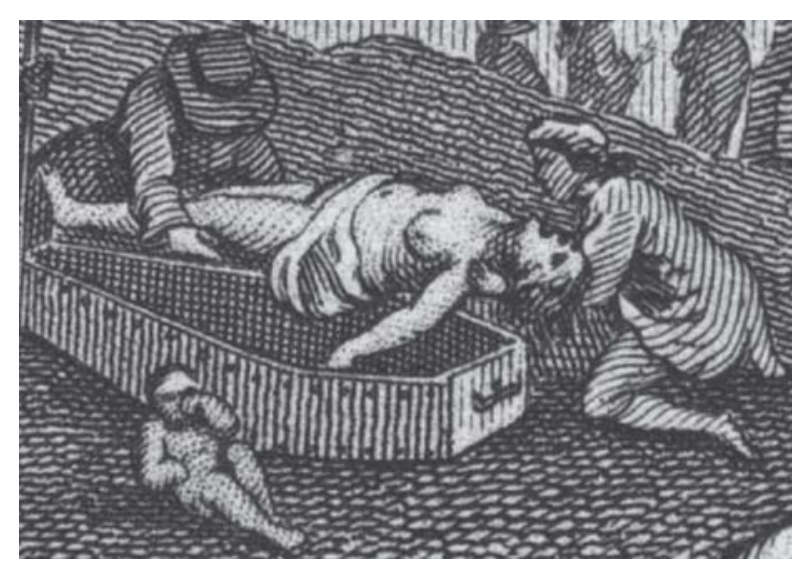

Figura 8: O funeral (ampliação dos setores 2A/1B da Figura 7; Hogarth, 1751b)

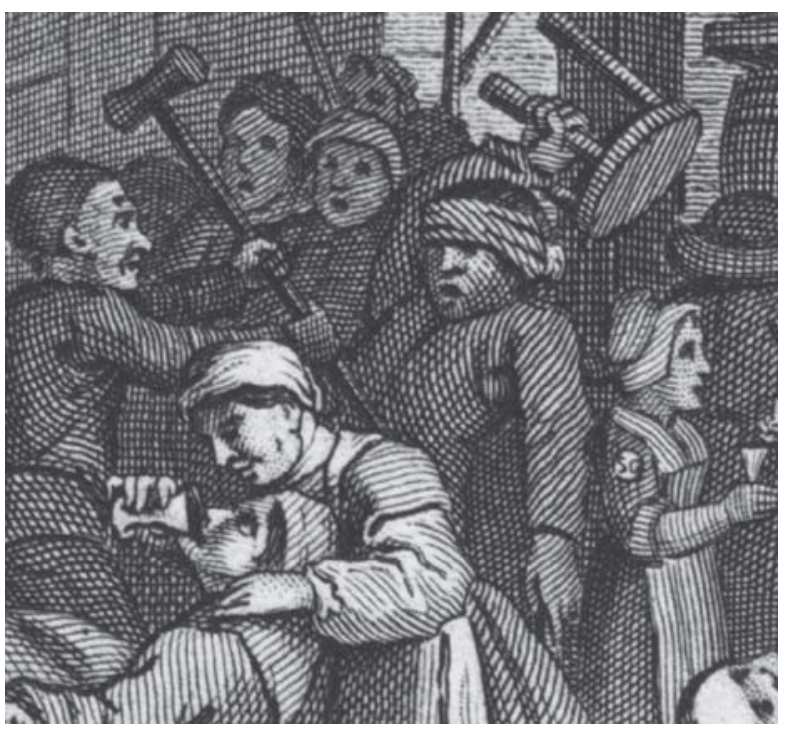

Figura 10: As brigas (ampliação do setor $2 \mathrm{C}$ da Figura 7; Hogarth, 1751b) 
sustento até o ponto de não poder mais retomar suas atividades profissionais: o homem entrega a serra, e a mulher, as panelas, provavelmente, de cobre. Em decorrência do vício, as pessoas acabam disputando 'alimentos' até com os animais (Figura 7, setor 2A); na verdade, o que sobra para dividir são ossos.

Tais circunstâncias resultam, no nível pessoal, em abandono da família e, finalmente, em suicídio (Figura 7, setor 1C) e outras formas de morte (Figura 7, setor 1B). No nível público, as ruas se tornam intransitáveis, e os prédios abandonados.

Além da ganância do penhorista (Figura 11), Hogarth critica especialmente os produtores de gim (Figura 12), chamados de destiladores assassinos (Killman Distillers).

Nem mesmo o próprio Estado ou, mais exatamente, a coroa inglesa, escapa da crítica de Hogarth, quando ele chama o gim de 'gim real' (Gin Royal), ou seja, do rei (Figura 13).

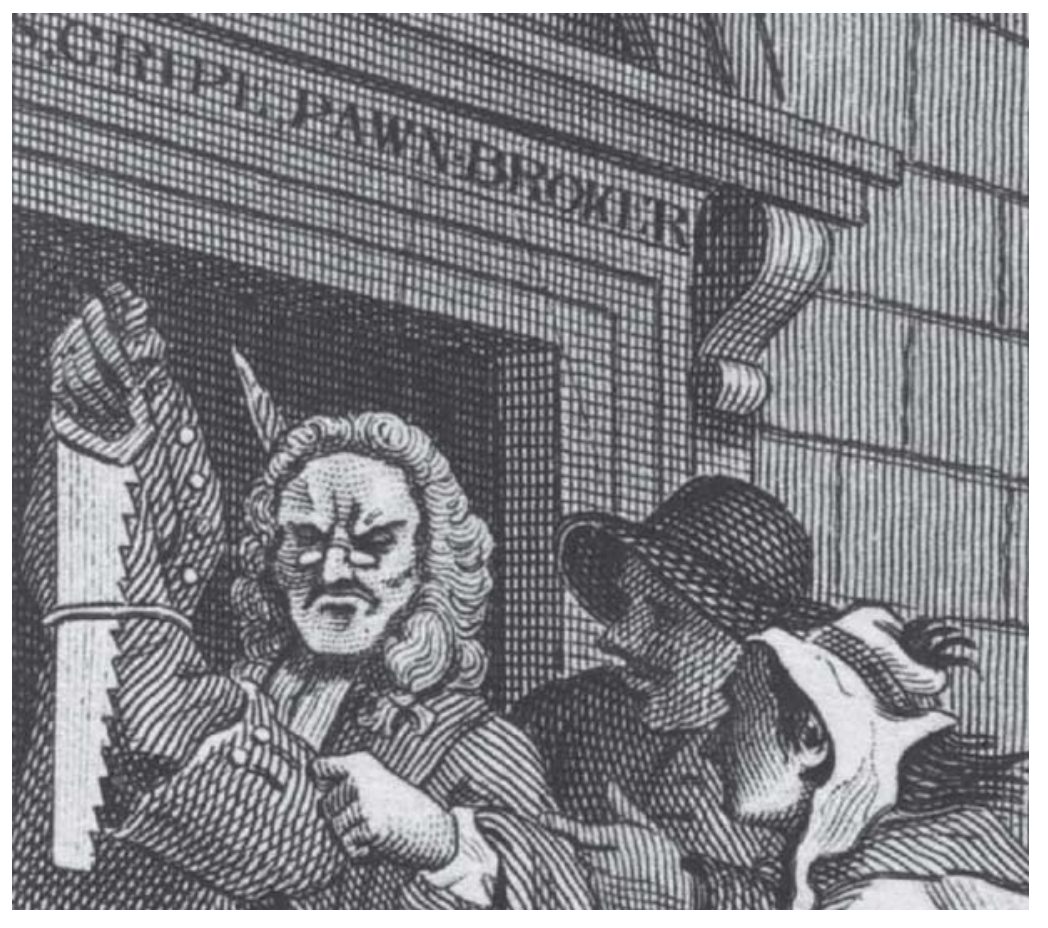

Figura 11: A casa de penhor (ampliação do setor 2A da Figura 7; Hogarth, 1751b)

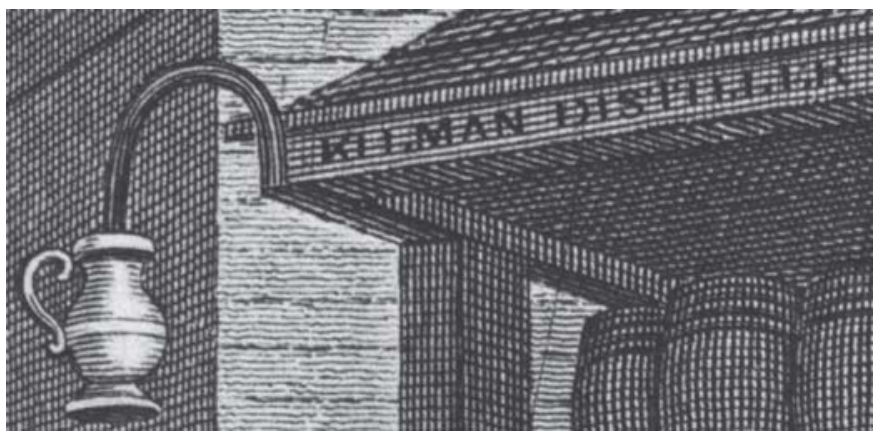

Figura 12: Os produtores de gim, classificados como assassinos (ampliação do setor $2 \mathrm{C}$ da Figura 7; Hogarth, 1751b)

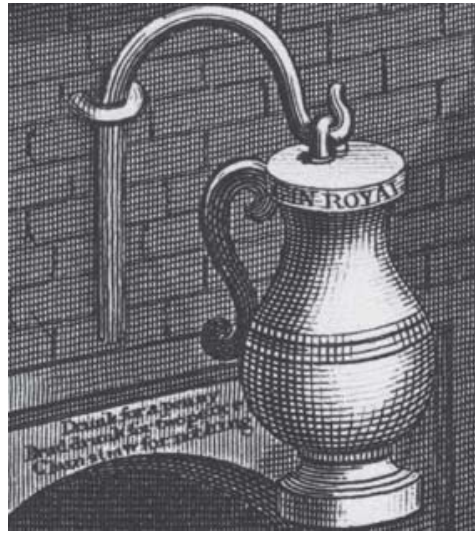

Figura 13:

A entrada da taverna (ampliação do setor $3 \mathrm{~A}$ da Figura 7; Hogarth, $1751 \mathrm{~b})$ 
Na entrada da taverna, se lê: "Bêbado por um penny / Bêbado até a morte por dois pennies / Uma cama de palha de graça" (Figura 13). O depósito do produtor de gim e a taverna são aproximados simbolicamente por uma caneca (Figura 7, setor 3A e 2B).

Em conjunto, as gravuras Beer Street (Figura 14) e Gin Lane (Figura 15) recorrem à metáfora bíblica do caminho estreito e do caminho largo.

Dessa forma, o artista condenou o gim e defendeu a cerveja.

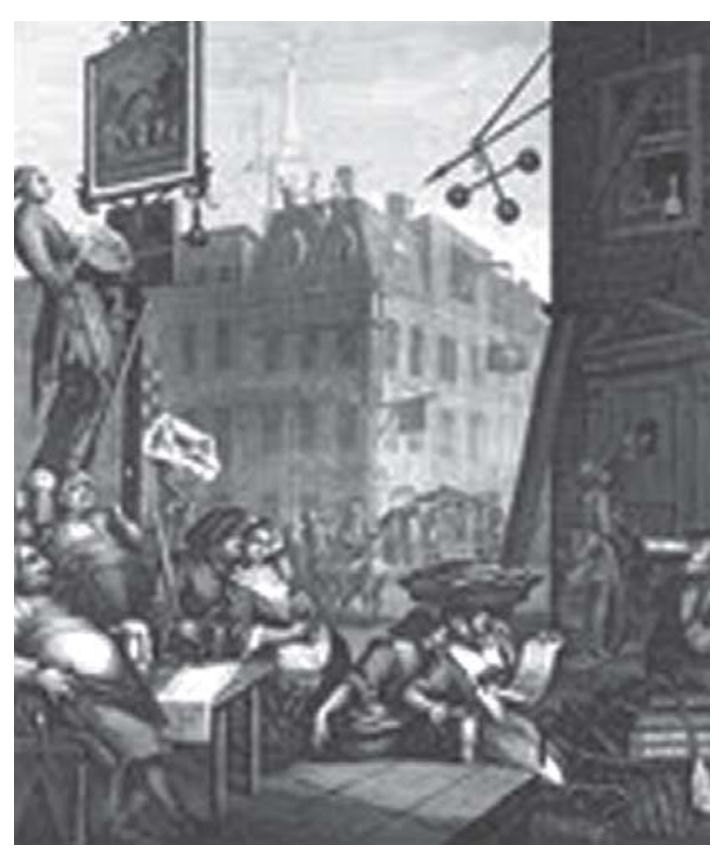

Figura 14: Beer Street (Hogarth, 1751a)

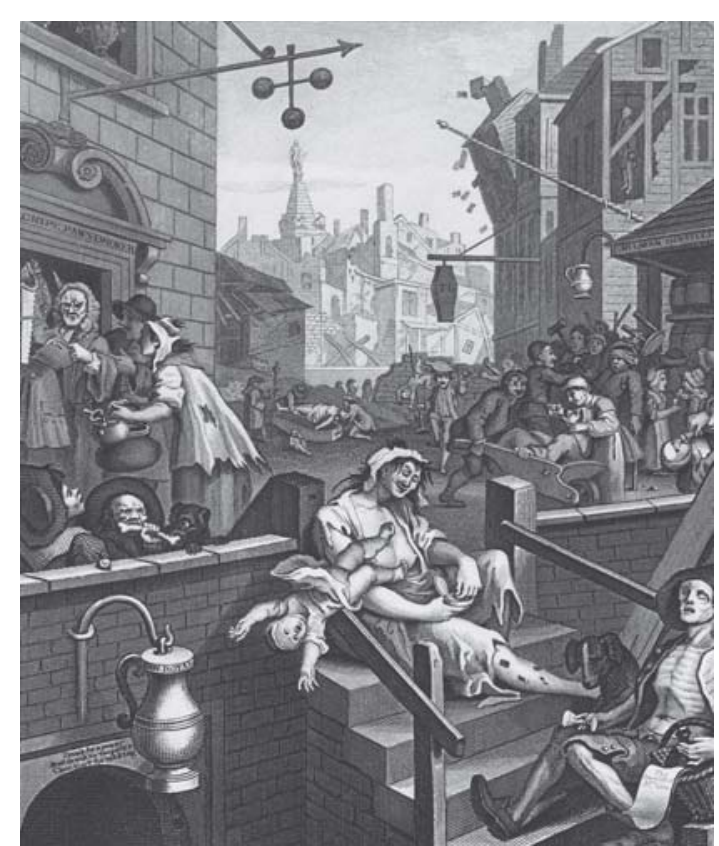

Figura 15: Gin Lane (Hogarth, 1751b)

\section{5 - O tema da temperança segundo as "Notas explicativas sobre o Novo Testamento": "o nosso Senhor permite o vinho"}

As "Notas explicativas sobre o Novo Testamento" (Wesley,1755a) eram uma livre adaptação de um comentário luterano de Albrecht Bengel (1858). Em Mateus 23:24 e I Timóteo 1:19, Wesley cita como exemplo do texto original (Bengel, 1858, p.248), o costume de beber licor. Já em João 2:2 encontramos a seguinte afirmação: "Jesus e seus discípulos foram convidados para a festa da boda - Cristo não exlui da convivência humana, mas a santifica. Água poderia ter saciado a sede, mas o nosso Senhor permitiu o vinho, especialmente em uma solenidade festiva". ${ }^{17}$ Em Lucas 1:15 encontramos a vinculação da abstinência ao consumo de bebidas fortes: "e não beberá vinho, nem bebida forte ... deve ser exemplar para a abstinência e autonegação, e muito mais os cheios do Espírito Santo"18; e em Efésios 5:18: "Onde houver excesso ... ou seja, o que leva à libertinagem de toda espécie. Mas vos enchei do Espírito Santo ... em todas as suas graças, que dá um prazer mais nobre do que o vinho pode dar" ${ }^{19}$ A expressão 'mais nobre' não só indica que o prazer não é exclusivo, mas está mais de acordo com um discurso a favor da temperança do que da abstinência. 


\section{1 - O tema da temperança segundo o "Diário": “Por que se condena vinho toto genere?"}

Os dois textos seguintes encontram-se no "Diário" de John Wesley (1777). Essa publicação tinha um sentido, se não apologético, ao menos explicativo, em defesa do movimento metodista e de seus líderes. Internamente, era uma forma de demonstrar transparência, e provavelmente também uma forma de defesa; era ainda, em grande parte, uma prestação de contas das ações, compreensões e experiências de Wesley.

No "Diário", referente ao dia 9 de julho de 1771, podemos ler (Wesley, 1777, p.40):

Eu li o engenhoso tratado das doenças crônicas do Dr. Cadogan. É certamente verdade, que 'muito poucas delas sejam herdadas', e que a maioria delas venha da indolência, intemperança, ou de paixões irregulares. Mas por que deveria condenar toto genere vinho, que é o mais nobre dos cordiais [existentes] na natureza? (grifo do original). ${ }^{20}$

William Cadogan (1711-1797) era médico formado pelo colégio dos médicos de Londres. Seu livro $A$ dissertation on the gout and all chronic diseases jointly considered as proceeding from the same causes (Uma dissertação sobre a gota, e todas as doenças crônicas, consideradas conjuntamente como procedentes das mesmas causas), de 1771, tratava de doenças reumáticas. A data do comentário de John Wesley mostra que ele adquiriu o seu exemplar no ano do lançamento do livro. Wesley cita do livro duas passagens (Cadogan, 1772, p.13$15,19)$ e se refere a sua estrutura em geral. ${ }^{21}$

Segundo Fraser (1992, p.160), a gota era considerada na época uma doença com certo status social:

Apesar de suas vítimas ficarem, muitas vezes, imobilizadas em casa durante semanas a fio, [a doença] não era vista, contudo, como inteiramente indesejável. Predominantemente uma doença masculina, por sua frequência nos corredores do poder e sua associação com estilo de vida extravagante, era percebida como socialmente desejável. ${ }^{22}$

Wesley, então, trata aqui de uma doença ligada ao estilo de vida das classes altas da época, não de uma doença popular e, de maneira geral, concorda com a proposta do autor: o ser humano "nunca deve perder de vista os três grandes princípios da saúde e de uma vida longa: atividade, temperança e paz de espírito" (Cadogan, 1772, p.71). O comentário específico - "Mas por que deveria condenar vinho toto genere" - refere-se provavelmente à frase: "o vinho sozinho produz mais doenças do que todas as outras causas juntas" (p.46). Diferentemente de Wesley, Cadogan (p.47) parece estar especialmente preocupado com o consumo contínuo, mesmo que moderado, de vinho:

Independentemente, portanto, daquilo que os defensores de um pouco de vinho a cada dia podem pensar, ou argumentar em favor dele, eles cometem, sem dúvida, um erro muito grande; seria certamente melhor e mais seguro beber uma garrafa e obter um momento de felicidade, uma vez por semana, e beber apenas água e uma cerveja leve em todos outros momentos; nesses intervalos a natureza consegue dominar totalmente, e se recuperar completamente. ${ }^{23}$

A prática proposta por Wesley distingue-se da sugestão de Cadogan em dois pontos: ele defende a temperança (quantidades menores são consideradas inofensivas) e certamente não teria aceitado o uso de álcool para procurar alcançar a felicidade. Entretanto os dois autores se aproximam ao aprovar o consumo de cerveja leve ao lado do de água. 
Outro comentário de Wesley, de 26 de junho de 1783, segue na mesma direção que o de 9 de julho de 1771: "Qui[nta-feira], 26: Depois que nossos amigos tinham providenciado de forma generosa vinho e frutas para a nossa pequena viagem, pegamos, numa linda manhã, o barco para Utrecht". ${ }^{24}$

Não há como saber, mas é possível supor que a generosidade não se referia à quantidade, mas à qualidade - e talvez ao preço - da bebida. Considerando o caráter público do Diário, pode-se concluir que John Wesley não escondeu do mundo o que ele considerava comum, aceitável, não prejudicial nem para a saúde, nem para a 'imagem' do movimento metodista: de vez em quando ele consumia vinho e não considerava esse hábito nocivo à saúde.

\section{3 - Tratado sobre a escassez de provisões: "imensas quantidades de milho são continuamente consumidas pela destilação"}

O tema de bebidas destiladas aparece novamente num texto de Wesley de 1773, dessa vez não por causa do efeito da embriaguez, mas em razão da sua relação com a fome. $\mathrm{O}$ tratado "Pensamentos sobre a atual escassez de provisões" analisa as razões de falta de trigo para alimentar o povo inglês, bem como as rebeliões ou os levantamentos espontâneos, esporádicos e locais de populações sem acesso à farinha.

I.1 Primeiramente pergunto: por que milhares de pessoas estão morrendo em toda a nação? Que é um fato eu sei, pois tenho visto com meus próprios olhos por todo canto da terra. Conheço pessoas que só podem comer uma refeição um dia sim, outro não. Conheço uma pessoa em Londres (que, embora há poucos anos tivesse todas as conveniências da vida) que hoje cata do esterco larvas fedorentas e as leva para casa para repartir com os filhos (Wesley, 1773, p.4). ${ }^{25}$

Depois dessa descrição da miséria da fome, Wesley (1773, p.6-7) parte para a análise:

I.3 Mas por que o alimento é tão caro? ... Por que o pão de milho tem um preço tão alto? ... a grande causa é porque imensas quantidades de milho são continuamente consumidas pela destilação. ... Some-se os destiladores de toda a Inglaterra e temos razão para acreditar que ... pouco menos da metade do trigo produzido no Reino é consumido a cada ano ..., convertendo-o em veneno mortal: veneno que destrói naturalmente não só a força e a vida, mas também a moral dos nossos compatriotas. ${ }^{26}$

E conclui:

I.6 Mas, por que o porco, as aves domésticas e os ovos são tão caros? Por causa da monopolização das fazendas; talvez o monopólio mais diabólico jamais introduzido neste Reino. A terra, que há alguns anos era dividida entre dez ou vinte pequenos posseiros e que lhes permitia sustentar suas famílias confortavelmente, é agora monopolizada por um grande fazendeiro (Wesley, 1773, p.11-12). ${ }^{27}$

Como solução, Wesley $(1773$, p.18, 19, 21) sugere uma política financeira que envolva mais aqueles que têm recursos:

II.4 ... (1) Colocar um imposto de dez libras sobre cada cavalo exportado à França; (2) Colocar um imposto adicional sobre as carruagens da aristocracia; II.8 ... (2) Acabar com todas as pensões inúteis ... Especialmente as ridículas [pensões] dadas a ... governadores de 
fortaleza ou castelos. Qual destas fortalezas serviu durante os últimos cem anos como algo além de um abrigo para gralhas e corvos?28

Entre as diversas razões apontadas como causas do aumento do preço do trigo e da farinha, são mencionados o uso do trigo para a alimentação de cavalos, considerados um produto de luxo, e o seu uso para a produção de bebidas como o gim; em relação às duas coisas, propõe-se a aplicação de impostos.

1783 - O tema da temperança segundo os Sermões: "Bebe nas refeições nada além de água ou uma cerveja leve"

Dois anos depois da mencionada viagem à Holanda, em 1781, John Wesley (1783, p.628-635) publicou no Arminian Magazine o sermão "Sobre a educação de crianças". Essa pregação faria parte da última coletânea dos sermões de Wesley publicada por ele mesmo em 1783.

O texto ganha em significado para nossa investigação porque não se posiciona de forma direta em relação ao tema da temperança, mas apresenta ao leitor uma ideia do cotidiano da educação familiar quanto ao consumo de álcool. O texto revela um costume, algo habitual, que não se discute, mas que se pratica.

Há, contudo, um problema de tradução. Para evidenciar o desafio, reproduzo um pequeno trecho do sermão 95, parágrafo 20, de Sermões de Wesley (Wesley, 2006). O texto em português refere-se a uma 'bebida leve', o original em inglês traz, literalmente, uma 'cerveja pequena' (small beer) ou cerveja leve (Quadro 1).

Quadro 1: Cerveja ou bebida leve?

Ela não precisa fazer com que eles conheçam o gosto do chá, até que eles tenham, pelo menos, nove ou dez anos de idade, ou façam uso de alguma outra bebida às refeições, a não ser água ou 'outra bebida leve'.
She need never, till they are a least nine or ten years old, let them know the taste of tea; or use any other drink at meals but water or 'small beer'.

Fonte: Wesley (2006).

Antes de atribuir tal diferença a um erro de tradução, é preciso reconhecer o dilema da tarefa ao se dirigir a pessoas do século XXI: nem em casas onde se consome álcool de forma moderada e dentro da perspectiva da temperança, oferecer-se-ia álcool para uma criança entre nove ou dez anos. Essa não era, entretanto, a situação no século XVIII. Já foi mencionado que uma cerveja leve era bebida para todas as horas do dia. Macfarlane (2003, p.128) lembra "que até crianças que dependiam da caridade recebiam cerveja leve" e que isso era considerado um ato de preservação da vida, justamente por causa da má qualidade da água. Trata-se de mais um texto que confirma o que foi dito até agora, mesmo que seja um exemplo que não deva ser reproduzido hoje.

\section{0 - O tema da temperança segundo o termômetro moral e físico de Benjamin Rush no Arminian Magazine}

O último texto editado por Wesley (1790b) sobre o tema é o mais abrangente. Trata-se do "A moral and physickal thermometer..." (Um termômetro moral e físico...) (Figura 16), 
publicado no Arminian Magazine, um jornal editado por Wesley desde 1778. Ele aborda tanto a cerveja leve como a cerveja forte, vinho, gim e muitas outras bebidas alcoólicas. O texto era, em grande parte, de Benjamin Rush (1745-1813), médico estadunidense preocupado com a saúde popular e um dos primeiros idealizadores do movimento de temperança nos EUA. Rush publicou o seu termômetro pela primeira vez em 1784 (Horrocks, 2008, p.181). Em seguida, reproduzimos a edição de uma versão levemente adaptada por John Wesley, sem mencionar o autor, publicada em 1790 no Arminian Magazine:

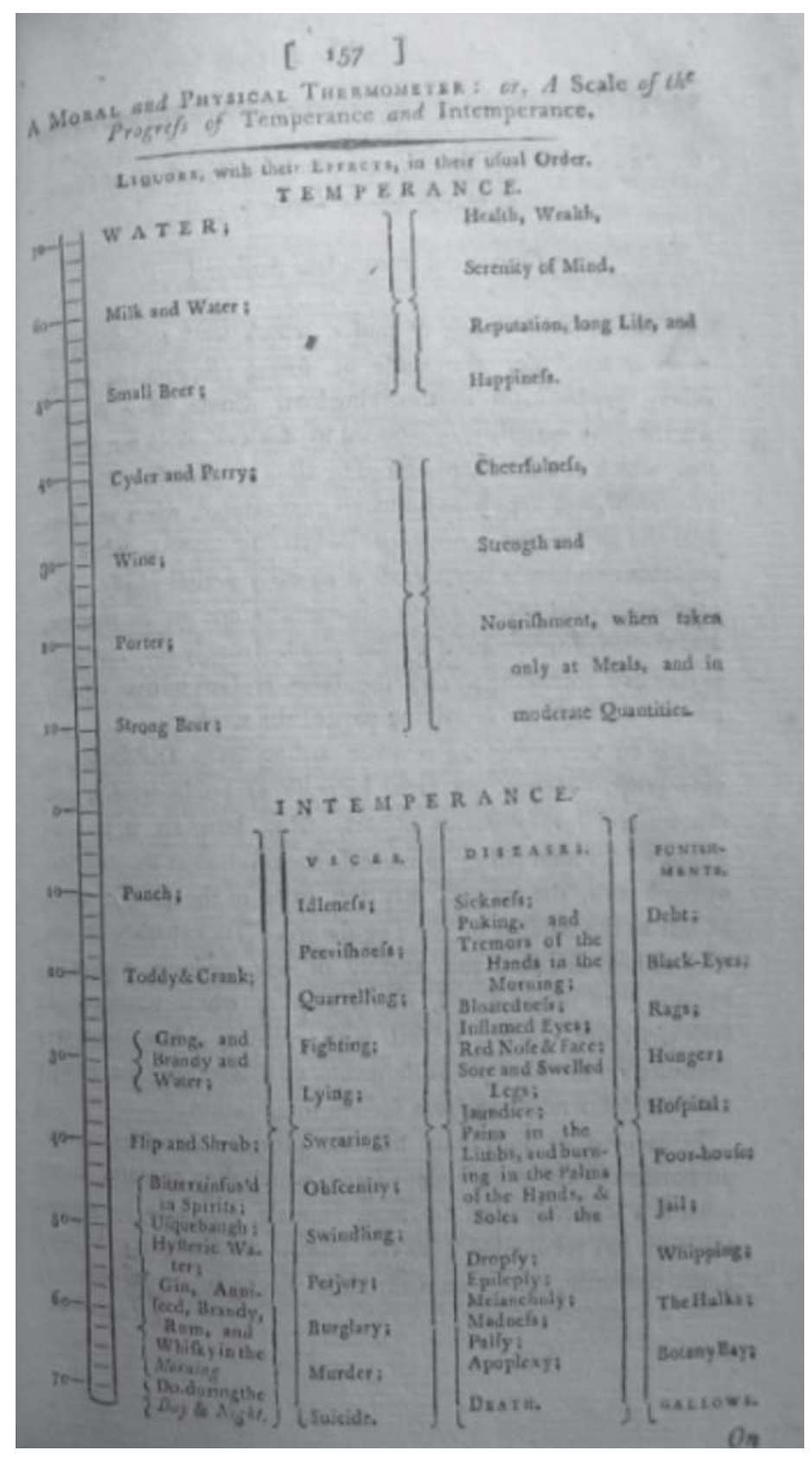

Figura 16: O termômetro físico e moral de Rush (citado em Wesley, 1790b, p.157) 
A versão de Wesley (1790b, p.157) é uma adaptação ao contexto inglês quanto às bebidas e às punições mencionadas que, por sua vez, segue uma edição de The European Magazine (Rush, 1789, p.185) ${ }^{29}$ (Figura 17) ou do The Gentleman's Magazine (1789, p.399), ambos do ano anterior.

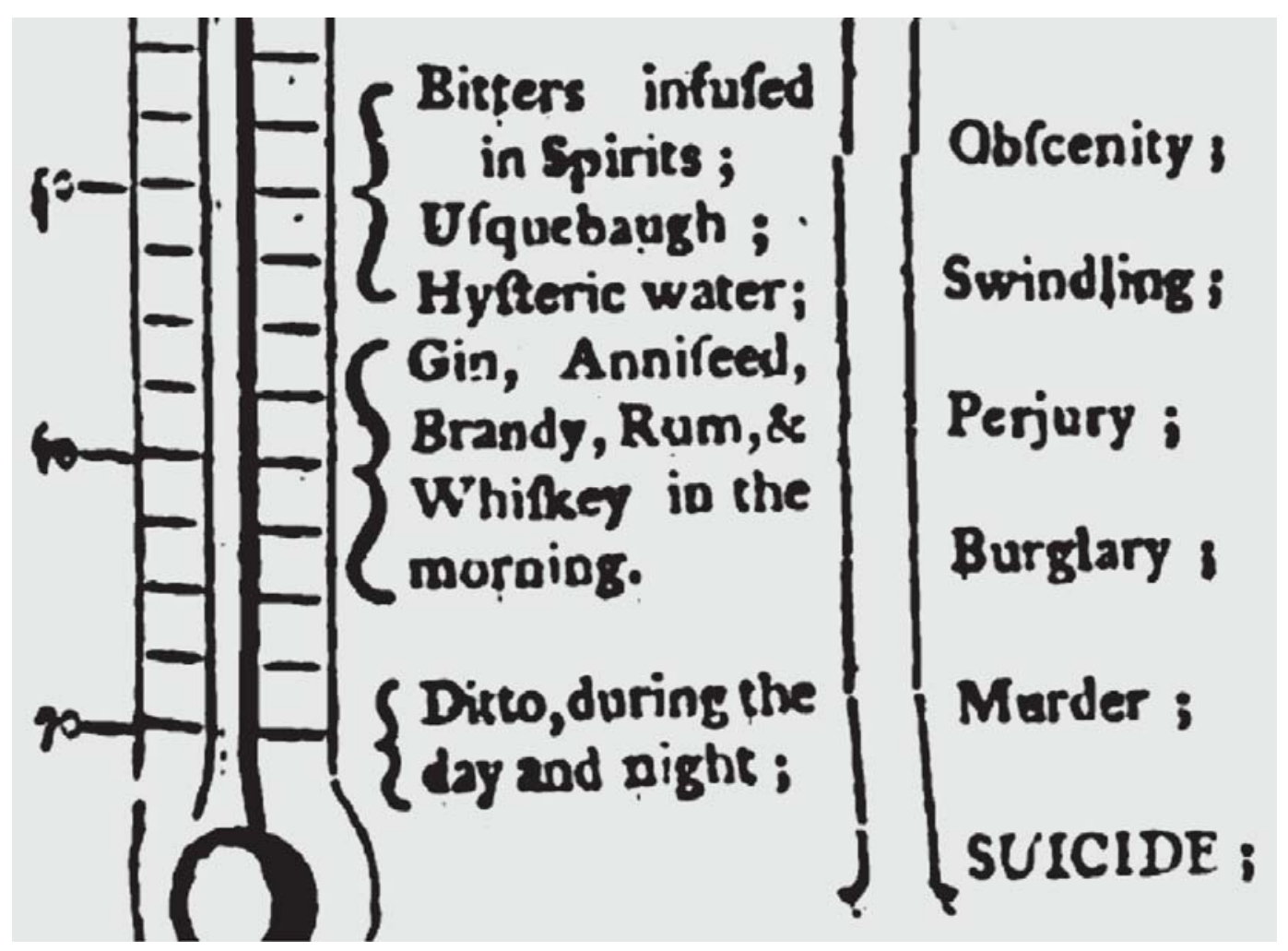

Figura 17: O termômetro da temperança em The European Magazine (Rush, 1789, p.185)

A parte referente à temperança é quase idêntica. Na versão inglesa, incluiu-se, ao lado da cidra, o perry, que era uma cidra à base de outras frutas que não a maçã. Na versão americana, encontram-se no campo referente ao leite e à água, ainda vinagre e água (vinegar and water) e melaço e água (molasses and water), ou seja, o extrato do doce da cana.

Segundo o termômetro, o consumo de "água" (+70) ou de "leite e água" (+60) garante "saúde, riqueza" e "serenidade da mente". Uma cerveja leve (+50) garante "reputação, vida longa e felicidade". Cidra (bebida à base de maçã, com 8,5\% de álcool) e perry (à base de frutas selvagens, semelhante à cidra, com teor alcóolico por volta de 8,5\%) (+40), vinho $(+30)$, porter $(+20)$ e cerveja forte $(+10)$ levam a "alegria", "boa constituição" [física] e são considerados "nutritivo(s), quando consumido(s) com as refeições em quantidades moderadas" (Rush, citado em Wesley, 1790b, p.157).

Já na parte da intemperança encontramos punch (-10), toddy (um licor escocês à base de gema de ovo) e creak (+20), grogue e brandy como parte de bebidas fortes (-30), flip (literalmente, 'cambalhota') e shrub (literalmente 'arbusto', ou seja, uma bebida destilada 
à base de frutas) (-40), amargo (bitter), uísque; aqua hysterica (brandy com ervas) (-50); brandy, rum e uísque consumidos pela manhã (-60) e brandy, rum e uísque consumidos dia e noite (-70). Esta última forma de consumo de bebidas alcoólicas levaria ao "suicídio", causaria "doenças mortais" e facilitaria comportamentos que levariam ao "enforcamento". (Rush, citado em Wesley, 1790b, p.157).

Cervejas de todo tipo - inclusive porter e cerveja forte (strong beer) -, vinho e cidra são considerados conciliáveis com a temperança. Mesmo assim, mantém-se uma clara distinção entre dois grupos: há uma preferência para a água e a cerveja leve (small beer), a única bebida alcoólica considerada fonte ilimitada de "saúde, riqueza, serenidade da mente, reputação, vida longa e felicidade" (Rush, citado em Wesley, 1790b, p.157). Já as outras bebidas requerem o manejo de costumes e hábitos alimentares para garantir "alegria, boa constituição e nutrição". Elas só não são prejudiciais quando "consumidas com as refeições e em quantidades moderadas", aspecto que nos lembra o comentário no livro Primitive physick: "Licores de malte (exceto uma cerveja clara ou leve, em seu período de validade) são bastante prejudiciais para pessoas frágeis [ou sensíveis]" (Wesley, 1747, p.XX). O consumo desse segundo grupo requer educação e disciplina, ou seja, técnicas culturais.

Depois desse "Termômetro físico e moral" segue no Arminian Magazine uma carta com o título: On premature death by the abuse of spirituous liquors (Da morte prematura, causada pelo abuso de bebidas alcoólicas) (Wesley, 1790a, p.158). O texto alerta:

Entre uma variedade de causas que acabam por abreviar a vida humana, o abuso de licores fortes, entre todas as outras, predomina neste Reino. ... Não é segredo algum que o lucro das destilarias é muito alto. Mas o fato de ser consistente com uma política sensata aumentar o lucro à custa da saúde, da moral, enfim, da vida de pessoas, é o segredo dessa legislatura. ${ }^{30}$

Mais uma vez, as políticas públicas e o lucro obtido com a venda de bebidas são criticadas. Na segunda parte, o texto dá dicas para tratar pessoas com uma intoxicação aguda, causada pelo abuso de álcool.

Vistos em conjunto, o termômetro e a carta representam uma análise e um alerta quanto aos hábitos do consumo de álcool, com o propósito de salvar vidas e orientar para comportamentos saudáveis que resultem em "saúde, riqueza, ... serenidade da mente, ... reputação, vida longa e felicidade" (Rush, citado em Wesley, 1790b, p.157).

O próprio movimento de temperança inglês, por meio de nada menos do que uma revista especializada no assunto, The Methodist Temperance Magazine, afirma, ainda em 1868, em relação a John Wesley:

Como reformador promovendo temperança estava muito mais à frente mesmo dos melhores homens da sua época. A respeito de nenhum outro tema ele se expressou com veemência maior do que a respeito dos costumes, relacionados às bebidas alcoólicas, dos seus compatriotas. É verdade que não era um 'completo abstêmio' no sentido como se usa a expressão atualmente, mas, em seus escritos, sanciona cada sentimento presente entre os reformadores da temperança cristã (Maunder, Garrett, Stephenson, 1868, p.12; grifo do autor). ${ }^{31}$

Contudo, esse posicionamento, característico do mundo anglo-saxão no fim do século XVIII - como o termômetro de temperança do americano Rush evidencia - já não 
representaria o consenso no final do século XIX. Enquanto o metodismo inglês continuava a propor a temperança, o metodismo estadunidense optou pela abstinência.

\section{Visão panorâmica dos posicionamentos de Hogarth e Wesley}

Na Tabela 1, unimos os resultados da nossa pesquisa, relacionando autores, gravuras, textos, conselhos e avaliações sobre tipos de bebidas.

Em termos gerais, consideramos que Hogarth e Wesley estão próximos quanto à aceitação da cerveja e à rejeição ao gim. Entretanto, Wesley favorece a cerveja leve e, uma vez que não rejeita de forma geral a cerveja forte ou porter, sugere verificar a constituição da pessoa antes de consumi-la. Já para Hogarth, a cerveja forte ou porter é símbolo de prosperidade, felicidade e bem-estar. Hogarth não menciona cidra nem vinho, enquanto Wesley as enquadra na mesma categoria da porter e da cerveja forte; todavia, na escala proposta por Rush, antes das duas, a cidra e o vinho teriam a preferência.

Tabela 1: Visão panorâmica: a avaliação por tipo de bebida em Hogarth e Wesley

\begin{tabular}{|c|c|c|c|c|}
\hline & Hogarth & & Wesley & \\
\hline Ano & Comentários & Bebida & Comentários & Ano \\
\hline \multicolumn{5}{|c|}{ Temperança } \\
\hline & - & Água & PP; TT: Saúde e prosperidade & $1747 ; 1790$ \\
\hline \multirow[t]{3}{*}{1751} & $\begin{array}{l}\text { Saúde; } \\
\text { prosperidade }\end{array}$ & Cerveja leve & PP; TT: Saúde e felicidade & $\begin{array}{l}1747 ; 1756 ; 1781 ; \\
1790\end{array}$ \\
\hline & - & Cidra & $\begin{array}{l}\text { TT: Alegria; deve ser } \\
\text { consumido com as refeições e } \\
\text { em quantidade moderada }\end{array}$ & 1790 \\
\hline & - & Vinho & $\begin{array}{l}\text { PP; Para tomar remédios; } \\
\text { NNT: O Nosso Senhor permite; } \\
\text { DI: De maneira geral não deve } \\
\text { ser rejeitado; } \\
\text { TT: Deve ser consumido com } \\
\text { as refeições e em quantidade } \\
\text { moderada }\end{array}$ & $\begin{array}{l}1746 ; \\
1747 \\
1755 a \\
1771 ; \\
1781 \\
1790\end{array}$ \\
\hline \multirow[t]{2}{*}{1751} & $\begin{array}{l}\text { Saúde; } \\
\text { prosperidade }\end{array}$ & Porter & $\begin{array}{l}\text { PP: O consumo depende da } \\
\text { constituição da pessoa; } \\
\text { TT: Deve ser consumido com } \\
\text { as refeições e em } \\
\text { quantidade moderada }\end{array}$ & $\begin{array}{l}\text { 1747-1791; } \\
1790\end{array}$ \\
\hline & & Cerveja forte & $\begin{array}{l}\text { PP: O consumo depende da } \\
\text { constituição da pessoa; } \\
\text { TT: Deve ser consumido com } \\
\text { as refeições e em quantidade } \\
\text { moderada }\end{array}$ & $\begin{array}{l}\text { 1747-1791; } \\
1790\end{array}$ \\
\hline \multicolumn{5}{|c|}{ Intemperança } \\
\hline 1751 & Morte & Gim etc. & $\begin{array}{l}\text { PP; TT; Proibido; prejudicial; } \\
\text { leva à morte }\end{array}$ & $1747 ; 1790$ \\
\hline
\end{tabular}

Fonte: Organizada pelo autor

Legenda: DI: “Diário" (Wesley, 1773); PP: Primitive physick (Wesley, 1747 a 1791); NNT: "Notas sobre o Novo Testamento” (Wesley, 1755a); TT: "Termômetro da temperança” (Wesley, 1790b) 
Helmut Renders

Expliquei, primeiro, a proximidade entre Wesley e Hogarth como representações do posicionamento majoritário ou cultural, comum na Inglaterra do século XVIII, com base no século XVII, o século que conheceu o gim em escala ampla somente na última década. O consumo de álcool não é categoricamente proibido, mas seus efeitos são observados 'empiricamente', não somente em níveis pessoais, mas também sociais. Em Hogarth transparece um argumento mais direcionado às classes burguesas: a cerveja inglesa é saudável e combina com a diligência (industry) ${ }^{32}$ necessária para construir uma vida boa; o gim holandês é prejudicial para as pessoas e para a sociedade.

Da mesma forma, os dois criticam, especialmente, os produtores e vendedores do gim, às vezes, até com uma linguagem muito próxima. Hogarth se refere ao produtor de gim como senhor assassino (Mr. Killman), Wesley chama os vendedores de envenenadores do público (public poisener). "Eles assassinam os súditos de sua majestade" (They murder His Majesty's subjects). Ambos lamentam o efeito público do consumo descontrolado: a destruição de famílias, o abandono das crianças, o aumento da criminalidade, a brutalização da vida, o que, em conjunto, resulta em muitas mortes.

Mesmo assim, há uma diferença. Hogarth, para começar, contrasta o gim dos pobres com a cerveja da burguesia, mas não menciona o vinho da aristocracia ou das classes altas, ao passo que Wesley não só menciona o vinho, como deixa transparecer que ele mesmo, ocasionalmente ${ }^{33}$, o consumia. Além disso, retoma o tema em três ocasiões e nunca proíbe seu consumo pessoal, desde que de forma moderada. ${ }^{34}$ Já a cerveja que prefere é produzida e consumida em casa, não a cerveja forte produzida por fábricas e consumida na rua e em tavernas.

\section{Considerações finais}

\section{O atual discurso religioso em defesa da abstinência e o resultado da pesquisa}

Esse exercício histórico foi realizado tendo em vista o contexto brasileiro. Nele encontramos graves problemas causados pelo uso inadequado de álcool e uma identidade religiosa protestante construída, em grande parte, sobre a defesa da abstinência. Para sustentar esse discurso, metodistas afirmam que sua escolha é a expressão fiel da proposta promovida por John Wesley. Concluímos, contudo, que a ligação indissolúvel entre santidade e sanidade por meio da abstinência não se baseia em John Wesley. Em termos técnicos históricos, trata-se de uma tradição inventada (Hobsbawm, Ranger, 1997). Nos escritos de John Wesley, o consumo, a produção e a venda de bebidas alcoólicas estão claramente divididos em três categorias:

(1) Plena liberação da small beer e, a partir de 1780, também da small ale, para ser produzidas e consumidas em casa (e, provavelmente, não para ser vendidas fora de casa);

(2) Liberação, sob certos cuidados, da cidra, do vinho e da cerveja forte ou porter: o consumo deve levar em conta a constituição da pessoa e a observação de hábitos saudáveis (por exemplo, o consumo deve ser feito junto com as refeições);

(3) Liberação do consumo de vinho e licores com prescrição medicinal; algumas dessas receitas constam no próprio guia Primitive physick. 
(4) Rejeição categórica de bebidas fortes por razões sociais, morais e porque o consumidor incorreria em risco de vida em consequência de embriaguez.

Os costumes britânicos em relação ao consumo pessoal de álcool, com sua ênfase na temperança ou moderação, diferente da ênfase estadunidense na abstinência, são, como os exemplos de Hogarth e John Wesley mostram, de longo prazo. Trata-se de um fenômeno sociocultural sob dupla aprovação religiosa: pela religião oficial da época - o anglicanismo de Hogarth - e pela religião marginal dos movimentos radicais de renovação religiosa e moral - o metodismo.

Essa leitura em relação à práxis do consumo particular de álcool se manteve em parte até o final da década de 1870, especialmente na Inglaterra. A sinceridade científica requer que seja corrigido o discurso a favor da abstinência categórica, baseado em informações ou concepções errôneas da própria tradição. Quem dispensa a necessidade da verificação dos fatos históricos para seu discurso, não somente sacrifica a sinceridade científica, mas o ideal da procura da verdade. Isso levou, em relação à avaliação do consumo de álcool, como Fuller (1996, p.84) corretamente descreve, à passar-se da "defesa de uma virtude cristã à insistência em um tabu social". ${ }^{35}$

\section{O problema do alcoolismo e o resultado da pesquisa}

Quanto à responsabilidade ética da ciência, não basta simplesmente encerrar aqui. Se, por um lado, se deve zelar pela verdade dos fatos, levando em conta seus contextos, razões sociais e expressões culturais, por outro lado, não se pode deixar de refletir sobre as consequências dos resultados dessa investigação científica e do seu propósito de corrigir uma apresentação errônea de dados históricos. A ética científica não funciona somente de forma deontológica, mas, também, teleológica, e não somente defende seus princípios, mas reflete também sobre suas possíveis consequências. A demanda ética do discurso científico faz contemplar essas duas dimensões.

Para a sociedade, também seria desastroso não refletir a respeito do problema do uso excessivo de álcool, inclusive de bebidas de baixo teor alcoólico. Fica a pergunta se a substituição da ênfase inglesa do século XVIII pela releitura estadunidense dos séculos XIX e XX trouxe resultados quanto à saúde pública. De fato existe hoje sobre essa questão um debate entre os especialistas em saúde pública. A comparação da eficácia de políticas públicas no combate ao alcoolismo entre países com uma tradição de proibição, de temperança ou de total ausência de políticas públicas não é consensual. Alguns autores apontam que a promoção da temperança talvez seja o caminho mais apropriado (Room, 1992), especialmente, quando essa moderação é acompanhada por uma reeducação quanto à escolha do tipo de bebida (Peele, 1993). Outros autores defendem políticas mais restritivas (Warner, Riviere, Carson, 2008; Warner, 2009).

Finalmente, precisa ser considerado o fato de que a acepção de 'dependência' como uma doença que requer tratamento era desconhecida na época de Hogarth e Wesley. Ela surge justamente no fim do século XIX, durante o desenvolvimento do discurso a favor da abstinência.

Diante desse quadro, abre-se aqui um importante campo de pesquisa, inclusive de estudos históricos comparativos. 


\section{NOTAS}

1 "Graphic satires and lay sermons." Nesta e nas demais citações de textos publicados em outros idiomas, a tradução é livre.

2 Trata-se da prancha 11 da série Industry and idleness (Esforço e preguiça) de 1747.

${ }^{3}$ Ambas as gravuras são reproduzidas na história do metodismo de Richard Heitzenrater (2006, p.126148).

${ }^{4}$ Não temos nenhum comentário de John Wesley sobre William Hogarth e suas gravuras.

5 "Until the late 17th century the social stratification of alcohol tended to be expressed in relation to courtly wine, urban beer and bucolic ale."

6 "First: By doing no harm, by avoiding evil of every kind, especially that which is most generally practiced, such as: The taking of the name of God in vain. The profaning the day of the Lord ... Drunkeness: buying or selling spirituous liquors, unless in cases of necessity ... Slaveholding; buying or selling slaves. ... Secondly: By doing good; by being in every kind merciful after their power; as they have the opportunity, doing good of every possible sort, and, as far as possible, to all men ...Thirdly: By attending upon all the ordnances of God; such are: The pulbic worship of God,. The ministry of the word, either read or expounded. The Supper of the Lord. Family and private prayer. Searching the Scriputres. Fasting or abstinence". Há pequenas mas importantes variações em outras edições. Por exemplo, onde se lê "comprar e vender" na edição da Igreja Metodista Episcopal Cristã lê-se "comprar ou vender"; na da Igreja metodista episcopal africana, "comprar ou o consumo"; na da Igreja metodista episcopal africana Sião, "ou uso"; na da Igreja metodista unida, "ou bebê-las". Em lugar de "em casos de necessidade", na edição da Igreja metodista unida lê-se "extrema".

7 "Neither may we gain by hurting our neighbour in his body. Therefore we may not sell anything which tends to impair health. Such is, eminently, all that liquid fire, commonly called drams or spirituous liquors. It is true, these may have a place in medicine. ... Therefore, such as prepare and sell them only for this end may keep their conscience clear. But who are they? Who prepare and sell them only for this end? Do you know ten such distillers in England? Then excuse these. But all who sell them ... to any that will buy, are poisoners general. They murder His Majesty's subjects by wholesale, neither does their eye pity or spare. They drive them to hell like sheep. And what is their gain? Is it not the blood of these men?"

${ }^{8}$ Foram consultadas a seguintes edições de Wesley (1747): $2^{a}$ ed., Bristol, 1750; 5 a ed., Bristol, 1755b; 8 a ed., Bristol, 1759; 9a ed., London, 1761; 12 ed., Bristol, 1765, p.XX; 13a ed., Bristol, 1768, p.XVIII;

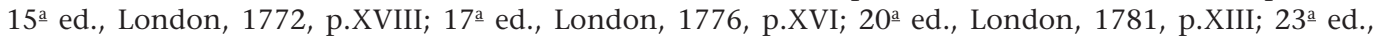
London, 1791, p.XII).

9 "[8] Strong liquors do not prevent the mitchiefs of a surfeit, no carry it of as safely as water. [9] Malt liquors (except clear small-beer of a due age) are exceeding hurtful to tender persons."

10 "Working-class diet of the 18 th century".

${ }^{11}$ A família Wesley também compartilhava desses hábitos do consumo, especialmente quando não dispunha de água fresca. Lightwood (1937, p.43) menciona que, em certa ocasião, a família de Charles Wesley ganhou uma casa mobiliada e com um estoque de cerveja leve.

12 "There seem to have been two major reasons for drinking beer rather than water. One was undoubtedly to avoid illness".

${ }^{13}$ Para Sinclair e Sinclair (2010, p.151-152) o sucesso do chá pode ser resultado da necessidade de ferver a água, que, desta forma, deixou de ser uma permanente fonte de doenças.

${ }^{14} 1$. Are you a Man? God made you a 'Man'. But you make yourself a 'Beast'. Not a Fool, not a Madman only. But a 'Swine', a poor, filthy Swine. ... 3. So you are now just 'fit for every work' of 'the devil' ... 4. Now, what should hinder the same Thing from befalling you, which befell him, who was ask'd, Which was the greatest Sin, Adultery, Drunkenness, or Murder? ... He said, Drunkeness was the least. Soon after, he got drunk. He then met with another Man's Wife, and ravish'd her. The Husband coming to help her, he murderd him. So Drunkenness, Adultery and Murder went together. ... 8. O do not aim at any Excuse. Say not, as many do, "I am no one's Enemy but my own." ... But it is not so. You are the Enemy of the King. .... A Drunkard is a public Enemy. 9. Above all, you are an enemy to God... 10. You are an Enemy to Christ... 11. O repent! See and feel what a wretch you are. ... Pray that you may know yourself inwardley and outwardly, all SIn, all Guilt, all Helplessness. Then cry out, Thou Son of David, have Mercy upon me! ... That I may love much, having had so much forgiven! 
${ }^{15}$ Segundo Dobson (1891, p.131) na primeira gravura este 'casal' de um homem com uma moça não existia.

${ }^{16} \mathrm{Na}$ Inglaterra, a pega era um pássaro conhecido por roubar objetos das pessoas.

17 "Jesus and his disciples were invited to the marriage - Christ does not take away human society, but sanctifies it. Water might have quenched thirst; yet our Lord allows wine; especially at a festival solemnity."

18 "And shall drink neither wine nor strong drink ... Shall be exemplary for abstemiousness and selfdenial; and so much the more filled with the Holy Ghost."

19 "Wherein is excess ... That is, which leads to debauchery of every kind. But be ye filled with the Spirit ... In all his graces, who gives a more noble pleasure than wine can do."

20 "I read over Dr. Cadogan's ingenious treatise on Chronical Distempers. It is certainly true, that 'very few of them are properly hereditary', that most of them spring either from indolence, or intemperance, or irregular passions. But why should he condemn Wine toto genere? Which is one of the noblest cordials in nature."

${ }^{21}$ Cadogan (1772): "Em relação à indolência" (p.22-30); "Em relação à intemperança" (p.30-51); "Em relação à vexação/paixão" (p.51-59); "Da cura da gota e todas as outras doenças crônicas e da recuperação de uma constituição fragilizada" (p.59-69).

22 "Although its victims were often immobilized at home for weeks on end, it was not, however, entirely unwelcome. Predominately a male disease, because of its frequency in the corridors of power and association with extravagant lifestyles, it was perceived as socially desirable."

23 "Whatever therefore the advocates for a little wine every day may think, or argue in favor of it; they are most undoubteldy in a very great error, and it were certainly much better and safer to drink a bottle and get a little merry once a week, drinking water only or small beer at all other times; in which interval nature might totally subdue it, and recover entirely."

24 "Thur. 26: Our friends having largely provided us with wine and fruits for our little journey, we took boat in a lovely morning for Utrecht."

25 "I.1 I ask, First, Why are thousands of people starving, perishing for want, in every part of the nation? The fact I know; I have seen it with my eyes, in every corner of the land. I have known those who could only afford to eat a little coarse food once every other day. I have known one in London (and one that a few years before had all the conveniencies of life) picking up from a dunghill stinking sprats, and carrying them home for herself and her children."

26 "I.3. But why is food so dear? ... Why does bread-corn bear so high a price? ... the grand cause is, because such immense quantities of corn are continually consumed by distilling. ... Add the distillers throughout England, and have we not reason to believe, that ... little less than half the wheat produced in the kingdom is every year consumed, ... by converting it into deadly poison; poison that naturally destroys not only the strength and life, but also the morals, of our countrymen."

27 "I.6. But why are pork, poultry, and eggs so dear? Because of the monopolizing of farms; perhaps as mischievous a monopoly as was ever introduced into these kingdoms. The land which was some years ago divided between ten or twenty little farmers, and enabled them comfortably to provide for their families, is now generally engrossed by one great farmer."

28 "II.4 ... (1) By laying a tax of ten pounds on every horse exported to France; (2) By laying an additional tax on gentlemen's carriages; II.8 ... (2) By abolishing all useless pensions ... Especially those ridiculous ones given to ... Governors of forts or castles; which forts have answered no end for above these hundred years, unless to shelter jackdaws and crows?"

${ }^{29}$ O editor do The European Magazine (1789, p.72) comenta ter encontrado esse "termômetro medicinal e moral" sugerido por um "amigo de outro país" no livro de Lettsom (1789).

30 "Among the variety of causes which tend to abbreviate human life, the use of strong liquors is, of all others, predominant in this kingdom. ... It is no secret that the revenue arising from Distilleries is very great. Hence the great increase of public-houses, and the demand for spirituous liquors. But, how far it is consistent with a sound policy to increase revenue at the expense of the health, of the morals, nay the life of the people, must be left to the wisdom of the legislature".

31 "As a temperance reformer John Wesley was far ahead of most even of the good men of his day. On no subject did he expressed himself more strongly than in reference to the drinking customs of his countrymen. 
Helmut Renders

It is true, he was not, in that sense in which the expression is now used, a 'total abstainer', but in his writings he endorses every sentiment of the Christian temperance reformer of the present time."

32 Junto à ideia da industry vem a explicação da pobreza pela preguiça dos pobres. John Wesley combateu esse preconceito com vigor (Renders, 2011, p.167-169). Sobre o conceito geral, ver Hobsbawm, 1968.

33 Talvez por razões econômicas, já que o vinho era caro.

${ }^{34}$ Até meados do século XIX, usava-se na Igreja metodista da Inglaterra o vinho, e não o suco de uva, na celebração eucarística. Ver o clima desfavorável ao movimento da temperança da Conferência Metodista ainda em 1841, em Bailey, Harvey, Brace (2007, p.148).

35 "Advocacy of a Christian virtue to the insistence upon a social taboo".

\section{REFERÊNCIAS}

BAILEY, Adrian R.; HARVEY, David C.; BRACE, Catherine.

Disciplining youthful methodist bodies in

Nineteenth-Century Cornwall. Annals of the

Association of American Geographers,

Washington, v.97, n.1, p.142-157. 2007.

BENGEL, Johann Albrecht.

Gnomon of the New Testament. v.4. Revised and edited by rev. Andrew R. Fausset. Edinburgh: T. \& T. Clark. 1858.

\section{CADOGAN, William.}

A dissertation on the gout, and all chronic diseases, jointly considered, as proceeding from the same causes; what those causes are; and a racional e natural method of cure proposed. London: Jos Sheppard. Disponível em: http://mcgovern. library.tmc.edu/data/www/html/collect/Gout/ dissert/distp.htm. Acesso em: 20 set. 2011. 1772.

CAMPBELL, Ted.

O essencial da doutrina metodista. Trad., Carlos Henrique Gonçalves. São Bernardo do Campo: Editeo. 2012.

DOBSON, Austin.

William Hogarth. London: S. Low, Marston. 1891.

FRASER, Kevin J.

William Stukeley and the gout. Medical History Cambridge, v.36, n.2, p.160-186. 1992.

FULLER, Robert C.

Religion and wine: a cultural history of wine drinking in the United States. Knoxville: University of Tennessee Press. 1996.

GATELY, Iain.

Drink: a cultural history of alcohol. New York: Gotham Books. 2008.

HEITZENRATER, Richard P.

Wesley e o povo chamado metodista. Trad., Cleide Zerlotti Wolf. São Bernardo do Campo: Editeo. 2006.
HOBSBAWM, Eric J.

Industry and empire: the making of modern

English society, 1750 to the present day. New York: Pantheon Books. 1968.

HOBSBAWM, Eric J.; RANGER, Terence. A invenção das tradições. Trad., Celina Cardim Cavalcante. Rio de Janeiro: Paz e Terra. 1997.

HOGARTH, William.

Credulity, superstition, and fanaticism. gravura. Aprox. $113 / 4$ x 14 pol. Disponível em: http:// upload.wikimedia.org/wikipedia/commons/3/ 3e/William_Hogarth_-

_Credulity\%2C_Superstition\%2C_and_Fanaticism2.png. Acesso em: 9 nov. 2010. 1762.

HOGARTH, William.

Beer Street. gravura. Aprox. 14 x 11 7/8 pol. Disponível em: http://upload.wikimedia.org/ wikipedia/commons/1/17/William_Hogarth__Beer_Street.jpg. Acesso em: 20 ago. 2010. $1751 \mathrm{a}$.

HOGARTH, William.

Gin Lane. gravura. Aprox. 14 x 11 7/8 pol.

Disponível em: http://upload.wikimedia.org/ wikipedia/commons/c/cd/Hogarth_07.jpg. Acesso em: 20 ago. 2010. 1751b.

HOGARTH, William.

The idle prentice executed at Tyburn. gravura. Aprox. 10 3/4 x 16 pol. Disponível em: http:// en.wikipedia.org/wiki/File:William_Hogarth__Industry_and_Idleness,_Plate_11;

The_Idle_\%27Prentice_Executed_at_Tyburn.png. Acesso em: 9 nov. 2010.1747.

HORROCKS, Thomas A.

Popular print and popular medicine: almanacs and health advice in early America. Amherst: University of Massachusetts Press. 2008.

LETTSOM, John Coakley.

History of some of the effects of hard drinking. London: H. Fry. 1789. 
LIGHTWOOD, James T.

Samuel Wesley, musician: the story of his life. London: Epworth Press. 1937.

MACFARLANE, Alan.

The savage wars of peace: England, Japan and the malthusian trap. Basingstoke: Palmgrave Macmillan. 2003.

MAUNDER, George; GARRETT, Charles; STEPHENSON, Thomas Bowman (Ed.). Mr. Wesley on the sale and use of spirituous liquor. The Methodist Temperance Magazine, London, ano 1, n.1, p.12. 1868.

NICHOLLS, James.

Drink: the British disease? History Today, London, v.60, n.1, p.10-17. 2010.

OLSEN, Kirstin.

Daily life in 18th-century England. Westport: Greenwood Press. 1999.

PAULSON, Ronald.

Hogarth: art and politics, 1750-1764, v.3.

Piscataway: Rutgers University Press. 1993.

PEELE, Stanton.

The conflict between public health goals and the temperance mentality. American Journal of Public Health, Washington, v.83, n.6, p.805-810. 1993.

RENDERS, Helmut.

Andar como Cristo andou: a salvação social em John Wesley. São Bernardo do Campo: Editeo. (2. ed., rev. e atualizada). 2011.

ROOM, Robin.

The impossible dream? Routes to reducing alcohol problems in a temperance culture. Journal of Substance Abuse, Norwood, v.4, n.1, p.91-106. 1992.

ROYAL COLLEGE...

Drugs: dilemmas e choices. London: Gaskell. 2000.

RUSH, Benjamin.

A moral e physickal thermometer. The European Magazine. London, v.16, n.10, p.185.

Disponível em: http://books.google.com.br/ books?id=tOkRAAAAYAAJ\&pg=PA153\&dq= $\mathrm{A}+$ moral+and+physickal+thermometer $\& \mathrm{hl}=\mathrm{pt}-$. Acesso em: 20 ago. 2010. 1789.

SALA, George Augustus.

William Hogarth: painter, engraver, and philosopher: essays on the man, the work and the time. London: Smith, Elder. 1866.

SINCLAIR, Thomas R.; SINCLAIR Carol Janas. Bread, beer and the seeds of change: agriculture's imprint on world history. London: Cabi. 2010.
THE GENTLEMAN'S...

The Gentleman's Magazine, London, v.59, Part 1, p.399. May 1789.

THOMPSON, Edward P.

A formação da classe operária inglesa: a maldição de Adão. v.2. Trad., Renato Busatto Neto, Cláudia Rocha de Almeida. São Paulo: Paz e Terra. 1987.

TURNER, Bryan S.

The body and society. Thousand Oaks: Sage. 1996.

WARNER, Jessica.

Temperance, alcohol, and the American evangelical: a reassessment. Addiction, San Francisco, v.104, n.7, p.1075-1084. Disponível em: DOI: 10.1111/j.1360-0443.2009.02616.x. Acesso em: 20 jul. 2012. 2009.

WARNER, Jessica; RIVIERE, Janine; CARSON, Jenny.

On wit, irony, and living with imperfection: how Britain said no to abstinence. American Journal of Public Health, Washington, v.98, n.5, p.814-822. 2008.

WESLEY, John.

Sermão 95. In: Renders, Helmut et al. (Ed.) Sermões de Wesley: texto inglês com duas traduções em português. São Bernardo do Campo: Editeo. CD-Rom. 2006.

WESLEY, John.

Primitive physick: or, an easy and natural method of curing most diseases. $23^{\text {rd }}$ ed. London: New Chapel. 1791.

WESLEY, John.

On premature death by the abuse of spirituous liquors. Arminian Magazine, London, v.13, n.4, p.158-160. 1790a.

WESLEY, John.

A moral and physickal thermometer or a scale of the progress of temperance or intemperance. Arminian Magazine, London, v.13, n.4, p.157. 1790b.

WESLEY, John.

Forty-four sermons. London: Wesleyan

Conference Office, J. Alfred Sharp. $4^{\text {th }}$ ed. 1787.

WESLEY, John.

On the education of children. Arminian Magazine, London, v.6, n. 11-12, p.628-635. 1783.

WESLEY, John.

Primitive physick: or, an easy and natural method of curing most diseases. $20^{\text {th }}$ ed. London: J. Paramore. 1781. 
WESLEY, John

An extract of the Rev. Mr. John Wesley's Journal: from Sep. 2, 1770, to Sep. 12, 1773. XVI.

London: Robert Hawes. 1777.

WESLEY, John.

Primitive physick: or, an easy and natural method of curing most diseases. $17^{\text {th }}$ ed. London: Robert Hawes. 1776.

WESLEY, John.

Thoughts on the present scarcity of provisions. London: Robert Hawes. Jan. 20. 1773.

WESLEY, John.

Primitive physick: or, an easy and natural method of curing most diseases. $15^{\text {th }}$ ed., London: Robert Hawes. 1772.

WESLEY, John.

Primitive physick: or, an easy and natural method of curing most diseases. $13^{\text {th }}$ ed. Bristol: William Pine. 1768.

WESLEY, John.

Primitive physick: or, an easy and natural method of curing most diseases. $12^{\text {th }}$ ed. Bristol: William Pine. 1765.

WESLEY, John.

Primitive physick: or, an easy and natural method of curing most diseases. $9^{\text {th }}$ ed. London: W. Strahan. 1761.

WESLEY, John.

Primitive physick: or, an easy and natural method of curing most diseases. $8^{\text {th }}$ ed. Bristol: John Grabham. 1759.

WESLEY, John.

Explanatory notes upon the New Testament. London: William Bowyer. 1755a.

WESLEY, John.

Primitive physick: or, an easy and natural method of curing most diseases. $5^{\text {th }}$ ed. Bristol: J. Palmer. 1755b.

WESLEY, John.

Primitive physick: or, an easy and natural method of curing most diseases. $2^{\text {nd }}$ ed. Bristol: Felix Farley. 1750.

WESLEY, John.

A word to a drunkard. [Bristol?]: W. Strahan. 1748.

WESLEY, John.

Primitive physick: or, an easy and natural method of curing most diseases. London: Thomas Tyre. 1747.

WESLEY, John.

A collection of receits, for the use of the poor. Bristol: Felix Farley. 1746.

WESLEY, John.

A word in season: or, advice to a soldier. Bristol: Felix Farley. 1745a.

WESLEY, John.

The nature, design, and general rules of the United Societies: in London, Bristol, Kingswood, and Newcastle upon Tyne. Bristol: Felix Farley. $1745 b$.

\section{$\rightarrow \rightarrow \rightarrow<<$}

